NBER WORKING PAPER SERIES

\title{
CAN THE MARKET MULTIPLY AND DIVIDE? NON-PROPORTIONAL THINKING IN FINANCIAL MARKETS
}

\author{
Kelly Shue \\ Richard R. Townsend \\ Working Paper 25751 \\ http://www.nber.org/papers/w25751 \\ NATIONAL BUREAU OF ECONOMIC RESEARCH \\ 1050 Massachusetts Avenue \\ Cambridge, MA 02138 \\ April 2019
}

We thank Gen Li, Huijun Sun, Kaushik Vasudevan, and Tianhao Wu for excellent research assistance and the International Center for Finance at the Yale School of Management for their support. We thank seminar audiences and discussants at the AFA, Arrowstreet Capital, Behavioral Economics Annual Meeting, D.E. Shaw, Federal Reserve Board, Harvard Business School, London Business School, London School of Economics, Lund University, Miami Behavioral Conference, Microsoft Research, Minnesota Accounting Conference, NBER Behavioral Finance, Penn State, Queen Mary University, Russell FTSE Conference, Russell Sage Behavioral Summer Camp, SFI Lausanne, Society of Quantitative Analysts, TCU Kneeley, Temple University, University of Oregon, UT Austin, Washington University St. Louis, Wharton, and Yale. We thank Nick Barberis, Justin Birru, John Campbell, James Choi, Stefano Giglio, Sam Hartzmark, Bryan Kelly, Toby Moskowitz, Matthew Rabin, and Andrei Shleifer for helpful comments. We are especially grateful to Shimon Kogan for sharing data and analysis. The views expressed herein are those of the authors and do not necessarily reflect the views of the National Bureau of Economic Research.

NBER working papers are circulated for discussion and comment purposes. They have not been peer-reviewed or been subject to the review by the NBER Board of Directors that accompanies official NBER publications.

(C) 2019 by Kelly Shue and Richard R. Townsend. All rights reserved. Short sections of text, not to exceed two paragraphs, may be quoted without explicit permission provided that full credit, including $\odot$ notice, is given to the source. 
Can the Market Multiply and Divide? Non-Proportional Thinking in Financial Markets

Kelly Shue and Richard R. Townsend

NBER Working Paper No. 25751

April 2019

JEL No. D03,D9,D91,G02,G12,G14,G4,G41

\begin{abstract}
$\underline{\text { ABSTRACT }}$
Nominal stock prices are arbitrary. Therefore, when evaluating how a piece of news should affect the price of a stock, rational investors should think in percentage rather than dollar terms. However, dollar price changes are ubiquitously reported and discussed. This may both cause and reflect a tendency of investors to think about the impact of news in dollar terms, leading to more extreme return responses to news for lower-priced stocks. We find a number of results consistent with such non-proportional thinking. First, lower-priced stocks have higher total volatility, idiosyncratic volatility, and market betas, after controlling flexibly for size. To identify a causal effect of price, we show that volatility increases sharply following pre-announced stock splits and drops following reverse stock splits. The returns of lower-priced stocks also respond more strongly to firm-specific news events, all else equal. The economic magnitudes are large: a doubling in a stock's nominal price is associated with a $20-30 \%$ decline in its volatility, beta, and return response to firm-specific news. These patterns are not exclusive to small, illiquid stocks; they hold even among the largest stocks. Non-proportional thinking can explain a variety of asset pricing anomalies such as long-run and short-run reversals, as well as the negative relation between past returns and volatility (i.e., the leverage effect). Our analysis also shows that the well-documented negative relation between risk (volatility or beta) and size is actually driven by nominal prices rather than fundamentals.
\end{abstract}

\author{
Kelly Shue \\ Yale School of Management \\ 165 Whitney Avenue \\ P.O. Box 208200 \\ New Haven, CT 06520-8200 \\ and NBER \\ kelly.shue@yale.edu \\ Richard R. Townsend \\ University of California, San Diego \\ Rady School of Management \\ 9500 Gilman Drive \\ La Jolla, CA 92093 \\ rrtownsend@ucsd.edu
}




\section{Introduction}

When evaluating how a piece of news should affect stock prices, rational investors should think in percentage terms rather than nominal dollar terms. Holding the equity size of a stock constant, the nominal share price has no real meaning, because the price depends on the arbitrary number of shares a firm's equity is divided into. However, dollar price changes in reaction to news are ubiquitously reported and discussed. For decades, newspapers such as the Wall Street Journal only published dollar price changes for stocks. More recently, popular stock-tracking applications, like the one pre-installed on the iPhone, have shown dollar price changes by default. Also, television networks such as CNBC routinely display tickers showing dollar price changes (see Figure 1 for examples). This emphasis on nominal price changes may both cause and reflect a tendency of investors to (at least partially) think that a given piece of news should correspond to a certain dollar change in price rather than a certain percentage change in price. In other words, investors may engage in non-proportional thinking.

To fix ideas, consider two otherwise identical stocks of the same size, one trading at $\$ 20 /$ share and another trading at $\$ 30 /$ share. Investors who think in dollar terms may believe that the same piece of good news, such as the arrival of a highly skilled CEO, should correspond to a $\$ 1$ increase in price for both stocks. ${ }^{1}$ Such non-proportional thinking would lead to a greater return response for the lower-priced stock than for the higher-priced stock. Similarly, with the arrival of additional news over time, non-proportional thinking would lead to greater return volatility for the lower-priced stock than the higher-priced stock, even if the two stocks were subject to the same sequence of news. These predictions apply broadly to all types of news, including news about cash flows as well as news about discount rates (e.g., a risk aversion or sentiment shock). Similarly, the predictions apply to news that is firm-specific as well as news that is aggregate in nature. To the extent that market returns reflect aggregate news, non-proportional thinking would also lead the returns of lower-priced stocks to more more strongly with the market, leading them to have higher market betas.

We begin by testing the volatility predictions from a simple model of non-proportional thinking.

\footnotetext{
${ }^{1}$ For example, the investor may recall that, when a firm announced the arrival of a new skilled CEO, its share price increased by $\$ 1$. When a different firm announces similar news, the investor mistakenly reasons that the new firm should also experience a $\$ 1$ increase in share price.
} 
We find that lower nominal share price is associated with higher total return volatility, as well as higher idiosyncratic volatility and market beta. The economic magnitudes are large: a doubling in share price corresponds to a $20-30$ percent reduction in these three measures of volatility. Of course, the negative relation between volatility and price could be attributable to other factors. In particular, small-cap stocks are known to have higher total volatility, idiosyncratic volatility, and market beta, possibly because small-cap stocks are fundamentally more risky. Small-cap stocks also tend to have lower nominal share prices, so the price-volatility relation in the data could be driven by size. However, we find that the negative price-volatility relation remains equally strong after introducing flexible controls for size. Moreover, the negative relation between size and volatility flattens by more than $80 \%$ after we introduce a single control variable for nominal share price. Similarly, the well-known negative beta-size relation in the data flattens toward zero after controlling for price. Thus, non-proportional thinking may explain the size-volatility and size-beta relations rather than the reverse. In addition, we show that non-proportional thinking can explain the "leverage effect" puzzle in which volatility is negatively related to past returns (e.g., Black, 1976; Glosten, Ravi, and Runkle, 1993). As prices decline, volatility increases because investors react to news in dollar units and thereby more strongly in percentage units.

Overall, we find that price has extremely high explanatory power for volatility in a manner that matches the predictions of a non-proportional thinking model. The negative volatility-price relation remains stable in magnitude after controlling for other potential determinants of volatility such as volume turnover, bid-ask spread percentage, market-to-book ratio, leverage ratio, and sales volatility. The results hold in the cross-section as well as in panel regressions that control for time-invariant stock characteristics. The results also hold in the recent time period and within a subsample limited to large-cap stocks. We also show that the results cannot be explained by tick-size limitations that constrain absolute dollar price changes to be above some minimum. In addition, we find that the magnitude of the volatility-price relation declines with institutional ownership and size, suggesting that the volatility-price relation represents a form of mispricing that is weaker among stocks that are easier to arbitrage.

While this collection of facts is consistent with non-proportional thinking, it remains possible 
that an omitted factor may drive the negative relation between price and volatility. To better account for potential omitted factors, we study how volatility changes around stock splits. Following a standard 2-for-1 stock split, the share price falls by $50 \%$. While the occurrence of a split in a given quarter is unlikely to be random (e.g., firms often choose to split their stock following good performance), the fundamentals that drive the split decision are likely to be slow-moving since all splits are pre-announced, usually by one month ahead of the split execution date. Our tests only require that firm fundamentals do not change on the split execution date. We find a sharp discontinuity around stock splits: total return volatility, idiosyncratic volatility, and market beta increase by approximately 30 percent immediately after a 2 -for- 1 split. Further, the volatility does not return to pre-split levels, even after six months. We also find that the magnitude of the jump in volatility can be cleanly sorted by the type of the split: 2-for-1 (in which price falls by 50\%) or 3-for-2 (in which price falls by 33\%). Moreover, volatility decreases sharply when prices rise in the case of reverse splits (e.g., when 2 shares become 1 ).

We also show that our results cannot be explained by changes in investor bases or media coverage. Previous research has argued that lower prices, and splits in particular, may attract speculative retail investors, who could drive up volatility. Along the same lines, media coverage of firms usually increases around splits, which could contribute to volatility. We show that these factors cannot generate the sharp, large, and persistent change in volatility observed in the data. First, we observe an immediate large jump in volatility after a split, even though we find that retail and institutional trading activity does not change dramatically on the split execution date. Second, the jump in volatility persists for many months, so it is unlikely to be caused by a temporary increase in media coverage. Third, simple models of speculative investors (e.g., Brandt et al., 2009) predict higher idiosyncratic volatility, but not necessarily higher market beta, which we also observe. In other words, stocks not only become more volatile after splits, but they also become more responsive to market news. Fourth, speculation and increased media coverage should lead to increased volume turnover following a split. Instead, we observe a sharp and persistent decline in volume following splits and the opposite pattern for reverse splits. This change in volume is instead consistent with a model in which some investors naively trade a fixed number of shares for each stock. Following 
a split, the share float doubles, so the number of shares traded relative to the float declines after splits and rises after reverse splits. ${ }^{2}$

In the remainder of the paper, we directly explore how return responses to news events vary with share price. We identify news events in three different ways. First, we identify news events through textual analysis using data from Boudoukh et al. (2018). On days where Boudoukh et al. (2018) identify value-relevant news events for stocks, we find that lower-priced stocks experience more extreme returns, consistent with non-proportional thinking. Of course, it is possible that lower-priced stocks simply tend to have more extreme news events. However, our analysis in this case is limited to S\&P 500 stocks due to data coverage. Among this set of large firms, it seems plausible that the distribution of news events would be similar across levels of nominal price.

Next, we study how return responses to quarterly earnings announcements vary with share price. On earnings announcement days, we find that lower-priced stocks experience more extreme returns. Again, it is possible that lower-priced stocks tend to have more extreme earnings news. However, in this case, we can control for the extremity of the news using the standardized earnings surprise relative to analyst forecasts. We find that the absolute magnitude of the return response to the same earnings surprise monotonically decreases with a stock's price prior to the announcement. Thus, the returns of lower-priced stocks respond more strongly to the same news, consistent with non-proportional thinking.

Finally, we show that non-proportional thinking is an important determinant of return reversals. If investors overreact to news for lower-priced stocks, then we would expect these stocks to experience stronger subsequent reversals as prices return to fundamentals. Consistent with non-proportional thinking, we find that both the long-run reversal anomaly documented by De Bondt and Thaler (1985) and the short-run reversal anomaly documented by Jegadeesh (1990) are stronger for lower priced stocks. Further, the magnitude of return reversals can be better sorted by price than by size.

Our results contribute to the literature in four ways. First, we document a new way in which thinking about changes in value in the wrong units can affect financial markets. Svedsäter, Gamble, and Gärling (2007) show that laboratory subjects report what amounts to a higher expected per-

\footnotetext{
${ }^{2}$ One might be concerned that the drop in volume turnover may reduce liquidity, which could contribute to higher volatility. However, we find similar results after controlling for changes in liquidity measures.
} 
centage change in price in reaction to news for hypothetical firms with lower nominal share prices. In this paper, we test whether these predictions hold in real financial markets and explore how non-proportional thinking can affect volatility and reversal patterns. In related work, Shue and Townsend (2017) show that the tendency to think about executive option grants in terms of the number of options granted rather than the Black-Scholes value contributed to the dramatic rise in CEO pay starting in the late 1990s. Birru and Wang $(2015,2016)$ show that nominal price illusion causes investors to mistakenly believe that lower-priced stocks have more "room to grow." Roger, Roger, and Schatt (2018) show that sell-side analysts issue more extreme forecasts for lower-priced stocks. ${ }^{3}$ Finally, our research is related to Baker and Wurgler(2004a,b), Baker, Nagel, and Wurgler (2007), and Hartzmark and Solomon (2017, 2018), which show that investors fail to incorporate dividend payouts when evaluating total returns. ${ }^{4}$

Second, we contribute to the literature on proportional (or relative) thinking (e.g., Thaler, 1980; Tversky and Kahneman, 1981; Pratt, Wise, and Zeckhauser, 1979; Azar, 2007; Bushong, Rabin, and Schwartzstein, 2015; and Lian, Ma, and Wang (2018)). This literature has largely focused on instances in which individuals think partly in percentage terms when they should think entirely in dollar terms. For example, consumers may be willing to travel to a different store to get a $\$ 10$ discount on a cheap product, but not for the same $\$ 10$ discount on an expensive product. These consumers incorrectly focus on the $\$ 10$ discount as a proportion of the good's retail price instead of comparing the dollar level of the discount to the cost of traveling to a different store. In contrast, we explore a financial markets setting in which investors think partly in dollar terms when they should think entirely in percentage terms. ${ }^{5}$ While the bias that we document may appear to be the opposite of that documented in the prior literature, the difference may in large part be due to the

\footnotetext{
${ }^{3}$ Roger, Roger, and Schatt (2018) interpret their results as consistent with analysts thinking about small numbers in a linear scale and large numbers in a logarithmic scale. However, we believe their evidence may also be consistent with a simple model of non-proportional thinking in which analysts make predictions for dollar changes in earnings per share, without fully scaling by share price.

${ }^{4}$ Our research is similar in spirit to the money illusion literature, which shows that households confuse the nominal and real value of money (e.g., Fisher, 1928; Benartzi and Thaler, 1995; Modigliani and Cohn, 1979; Ritter and Warr, 2002). In this paper, we show that investors focus on dollar units instead of percentage units. Our research is also related to the broader literature on behavioral finance, particularly Lamont and Thaler (2003), which asks the question of whether investors can "add and subtract," and is the inspiration for the title of this paper.

${ }^{5}$ There are other financial market settings that resemble a consumer choice problem, where investors should think in levels. For example, Lian, Ma, and Wang (2018) show that investors should think in levels when comparing the returns of risk-free versus risky assets, but may mistakenly think in proportions.
} 
type of thinking called for under the rational benchmark in each setting. People may think partially in percentages and partially in dollars, leading to mistakes in settings in which they should think entirely in dollars (consumer choice problems) or in percentages (when pricing financial assets).

Third, our findings shed light on the potential origins of volatility in financial markets. Since Shiller (1981), academics have explored the question of what factors determine volatility and risk. Our results suggest that non-proportional thinking may be an important part of the explanation. Moreover, we show that several stylized facts in asset pricing, such as the leverage effect as well as the size-volatility and size-beta relations in the data can be reinterpreted through the lens of non-proportional thinking.

Fourth, we offer a new explanation of over and underreaction to news and subsequent drift patterns in asset prices. The existing literature in behavioral finance has mainly viewed over and underreaction to news through the lens of limited attention (e.g., Hirshleifer and Teoh, 2003), incorrect weighting of news relative to one's priors (e.g., Barberis, Shleifer, and Vishny, 1998), or mistaken beliefs regarding extrapolation and reversals (e.g., Greenwood and Shleifer, 2014; Lakonishok, Shleifer, and Vishny, 1994; Hong and Stein, 1999). Non-proportional thinking offers a complementary explanation: over and underreaction to news can also be caused by investors thinking about news in the wrong units.

Finally, we note that some of the basic empirical facts collected in this paper have been individually shown in previous research. However, the previous literature has often presented these facts as puzzles in the data. For example, an increase in volatility following splits was discussed in early work by Ohlson and Penman (1985), and the general negative relation between price and volatility is well-known in the asset pricing literature (e.g., Black, 1976). Our contribution is to offer a new explanation that unifies a large number of facts and puzzles, and to cast doubt on supposedly robust facts, such as the view that size is a fundamental determinant of risk. With a model of non-proportional thinking in mind, we can also present a more targeted set of empirical tests to distinguish our hypothesis from potential alternative explanations. 


\section{A Simple Model}

Consider a stock with current share price $P$, just before news is released. Suppose news $Z$ is released that contains information relevant for the valuation of the stock. We assume that if markets are fully efficient and rational, the release of news $Z$ should imply a $\delta$ percentage change in the price of the stock. In other words, $\delta$ is the rational return response to the news. However, non-proportional thinking may lead investors to apply a heuristic and think that news $Z$ should move prices by a dollar

amount $X$. In this case, the return response to news would be $\frac{X}{P}$ rather than $\delta$. A return response of $\frac{X}{P}$ would represent the most extreme form of non-proportional thinking. However, investors may only engage in partial non-proportional thinking. To capture this, we consider a return response function that nests proportional and non-proportional thinking:

$$
r=\delta\left(\frac{\eta_{0}}{P}\right)^{\theta}
$$

where the parameter $\eta_{0}$ is a constant equal to $\frac{X}{\delta}$ and the parameter $\theta \in[0,1]$ captures the extent to which investors engage in non-proportional thinking. When $\theta=0$, investors are fully rational and the return response is $r=\delta$. When $\theta=1$, the return response is $r=\frac{X}{P}$. In the presence of non-proportional thinking $(0<\theta \leq 1)$, Equation 1 implies that the magnitude of the return response to news, $|r|$, will be greater, the lower the stock's price, $P$. One interpretation of $\eta_{0}$ is as the price level such that the dollar response $X$ corresponds to the rational return response $\delta$, even when investors engage fully in non-proportional thinking (i.e., $\theta=1$ ).

To move closer to an estimating equation, Equation 1 can also be expressed linearly by taking logs:

$$
\log (|r|)=\log (|\delta|)+\theta \log \left(\eta_{0}\right)-\theta \log (P)
$$

Of course, we cannot typically observe $\delta$ and $\eta_{0}$ in the data. However, to the extent that they are orthogonal to $P$, we can still estimate $\theta$ from Equation 2, omitting these variables. Given that nominal share prices are fairly arbitrary, it may be plausible that $P$ would be orthogonal to $\delta$ and $\eta_{0}$, especially after conditioning on other observable stock characteristics (e.g., size), or by comparing 
the same stock immediately before and after a stock split. In some tests, we also explicitly control for the magnitude of the news shock or restrict to a sample of S\&P 500 firms for which is it more plausible that $\delta$ is orthogonal to $P .^{6}$

The model also delivers predictions for a stock's return volatility. If we allow for a sequence of iid news arriving over time corresponding to volatility $\sigma_{\delta}$, Equation 1 implies that:

$$
\sigma_{r}=\sigma_{\delta} \cdot\left(\frac{\eta_{0}}{P}\right)^{\theta}
$$

In the presence of non-proportional thinking $(0<\theta \leq 1)$, this means that a stock's volatility will be greater, the lower the stock's price. This can be also be expressed in log form as:

$$
\log \left(\sigma_{r}\right)=\log \left(\sigma_{\delta}\right)+\theta \log \left(\eta_{0}\right)-\theta \log (P)
$$

The prediction that lower-priced stocks should have higher volatility applies to different measures of volatility, including total return volatility, idiosyncratic volatility, and absolute market beta. Lower-priced stocks would have higher idiosyncratic volatility due to their greater responsiveness to firm-specific news. They would also have higher absolute market beta due to their greater responsiveness to aggregate news. Note that non-proportional thinking amplifies the absolute value of market beta. For example, if a stock's true beta is negative and aggregate news is positive, the stock's share price should drop and the share price should drop by more if investors overreact to the news. Together, greater idiosyncratic volatility and absolute market beta would lead to greater total volatility.

This simple model applies to reactions to news where "news" is defined broadly. In addition to cash flow news, non-proportional thinking may also bias investor reactions to discount rate news, such as shocks to risk aversion or sentiment. For example, investors may reduce their valuation of stocks following a risk aversion shock. If investors react to the risk aversion news in dollar units, then the magnitude of the return reaction will be larger for lower-priced stocks, all else equal.

\footnotetext{
${ }^{6}$ We also acknowledge that assuming that $\delta$ and $\eta_{0}$ are orthogonal to $P$ may be an oversimplification of a more complex model that actually drives investor behavior. Nevertheless, we show in Figure 2, Panel B, that a model with these assumptions fits the data reasonably well.
} 
Because news events are difficult to observe systematically, we begin our analysis of nonproportional thinking by testing our predictions for the relation between nominal price and return volatility, estimating variants of Equation 4. We then use several approaches to identify news events. Using these identified news events, we test our predictions about the relation between nominal price and return responses to news, estimating variants of Equation 2.

\section{Data}

The sample period for our baseline analysis runs from 1926-2016. However, the beginning of the sample period for each empirical test varies depending on when coverage begins for supplementary data sources used in the analysis. We also show that our results are robust across different time periods. Summary statistics for our key variables can be found in Table 1.

\section{Stock Market Data}

We obtain stock market data from CRSP, which contains information relating to returns, nominal share prices, stock splits, daily high and low, volume, bid-ask spread, and market capitalization. Data on factor returns and size category cutoffs come from the Ken French Data Library. We restrict the sample to stocks that are publicly traded on the NYSE, American Stock Exchange, or NASDAQ. We also restrict the sample to assets that are classified as common equity (CRSP share codes 10 and 11).

In our baseline tests, we measure stock $i$ 's total return volatility in month $t$ as the annualized standard deviation of its daily returns within that month. We measure stock $i$ 's market beta in month $t$ by regressing its daily excess returns within that month on market excess returns. Because non-synchronous prices have been shown to have a big impact on short-horizon betas, we follow Dimson (1979) and include both current and lagged market excess returns in the regressions, estimating beta as the sum of the slopes on all lags. Specifically, we include four lags of market returns, imposing the constraint that lags $2-4$ have the same slope to reduce the number of parameters, as in Lewellen and Nagel (2006). We measure idiosyncratic volatility as the annualized standard deviation of the residuals from these regressions. 
To classify stocks by nominal share price, past returns, etc., we always use lagged information so as to avoid look-ahead bias. To reduce the influence of outliers, we restrict our baseline analysis to stock-months where (1) there are at least 15 trading days with non-missing return data in CRSP and (2) there is variation in the stock's price (i.e., the stock price is not the same on all trading days within the month) and (3) the nominal stock price at the end of the previous month was not in the top or bottom $1 \%$ of stock prices that month. We also examine changes in volatility at a daily frequency. In this case, we measure volatility as a stock's intraday price range percentage $\left(100 \times \frac{\text { High }- \text { Low }}{\text { High }}\right)$.

\section{Firm Accounting Data}

We use accounting data to control for firm characteristics. These data come from the COMPUSTAT Quarterly Fundamentals file. Coverage begins in 1961. The primary control variables we construct are sales volatility, market-to-book ratio, and leverage. We define sales volatility as the standard deviation of year-over-year quarterly sales growth during the previous four quarters. ${ }^{7}$ In cases where data are missing for some of the previous four quarters, we compute the standard deviation based on the non-missing quarters, conditional on there being more than one non-missing quarter. We define the market-to-book ratio as market capitalization (csho*prcc_f) plus the book value of assets (at) less shareholder equity (seq), all divided by the book value of assets (at). We define leverage as the ratio of short-term and long-term debt $(\mathrm{dlc}+\mathrm{dltt})$ to the book value of assets (at).

\section{Institutional and Retail Ownership}

Data on institutional ownership come from the Thomson Institutional Manager Holdings file, which is based on quarterly $13 \mathrm{f}$ filings. Coverage begins in 1980. Each quarter, we sum up the number of shares of each stock held by $13 \mathrm{f}$ filers and divide by shares outstanding to get institutional ownership percentages. Data on the characteristics of a firm's retail shareholders come from Odean's (1998) "Large Discount Broker" database.

\footnotetext{
${ }^{7}$ For each quarter, we compute the growth of sales (sale) over the year-ago quarter. We consider year-over-year sales growth to be undefined if sales are reported to be negative in one of the two quarters.
} 


\section{Option-Implied Volatility}

Data on option-implied volatility and option prices come from OptionMetrics, which computes implied volatility over different horizons based on traded options of varying maturities. Coverage begins in 1996.

\section{News Events}

To identify news events, we use data from Boudoukh et al. (2018), which identifies value-relevant events by applying a machine learning algorithm to the text of articles from Dow Jones Newswire. News events are divided into two groups: events that the algorithm can place into a particular category and events that it is unable to categorize. The Boudoukh et al. (2018) data are limited to S\&P 500 stocks, with coverage beginning in 2000.

\section{Earnings Announcements}

Data on quarterly earnings announcements come from the $\mathrm{I} / \mathrm{B} / \mathrm{E} / \mathrm{S}$ detail file. Coverage begins in 1983. These data provide information on analyst forecasts of earnings per share, along with the actual announced earnings per share. Following the literature (e.g., Mendenhall 2004; Jegadeesh and Livnat 2006), we define standardized unexpected earnings (SUE) as:

$$
S U E_{i, t}=\frac{\left(A E_{i, t}-F E_{i, t}\right)}{\sigma_{i, t}}
$$

where for firm $i$ in quarter $t, A E_{i, t}$ represents the actual earnings, $F E_{i, t}$ represents mean forecasted earnings, and $\sigma_{i t}$ represents the standard deviation of analyst forecasts. Thus, $S U E_{i, t}$ is a measure of how surprising an earnings announcement was, given the distribution of analyst forecasts. It is only defined for earnings announcements with multiple forecasts. We compute the variables $F E_{i, t}$ and $\sigma_{i, t}$ using only the most recent forecast of each analyst prior to the earning announcement. To avoid using stale information in our measure of analyst expectations, we exclude analyst's forecasts that are made more than 60 days prior to the announcement. Our results remain similar if we exclude forecasts made more than 30 days prior to the announcement. 


\section{Results: Volatility}

\subsection{Prices, Total Volatility, Idiosyncratic Volatility, and Market Beta}

We begin by exploring how return volatility varies with share price. Using data at the stock-month level, we estimate the following regression:

$$
\log \left(\operatorname{vol}_{i, t}\right)=\beta_{0}+\beta_{1} \log \left(\text { price }_{i, t-1}\right)+\text { controls }+\tau_{t}+\epsilon_{i t}
$$

We regress each stock $i$ 's volatility in month $t$ on the stock's nominal share price at the end of the previous month, calendar-year-month fixed effects, and additional control variables. Volatility can represent total volatility, idiosyncratic volatility, or market beta. We measure volatility and nominal share price in logarithm form because a simple model of non-proportional thinking implies that volatility should change proportionately with the share price, leading to a linear log-log relation. Control variables can include the log of the firm's size (measured as total market equity) in the previous month or indicator variables for 20 size categories based on the market capitalization of the stock relative to the size breakpoints for each year-month from the Ken French Data Library. The sample excludes observations with extreme lagged prices (the bottom and top $1 \%$ of prices

each month). To account for correlated observations, we double-cluster standard errors by stock and year-month.

We present our baseline results in Table 2. Consistent with the predictions from a simple nonproportional thinking model, we find that higher nominal share price is associated with lower total return volatility. The negative coefficient on price remains highly significant and stable in magnitude as we introduce control variables for size (either as the log of lagged market capitalization or with 20 size category indicators based on lagged market capitalization). The results hold in the cross section (with time fixed effects and without stock fixed effects) and in the time-series (with both time and stock fixed effects), as shown in Panels A and B, respectively. The economic magnitudes are also quite large. With the full set of control variables in column (4), a doubling in share price is associated with a $34 \%$ decline in volatility in the cross section and a $27 \%$ decline in volatility in the time-series (i.e., within stock over time). While our illustrative model is not intended to offer an 
exact match to the data, we can interpret these coefficient estimates as implying that $\theta$ in Equation 4 is approximately 0.3 . In other words, investors display an intermediate level of non-proportional thinking.

In Table 3, we find similar empirical patterns after replacing the dependent variable with idiosyncratic volatility and market beta. The economic magnitudes are again large. With the full set of control variables in column (4), a doubling in share price is associated with a $35 \%$ decline in idiosyncratic volatility and a $31 \%$ decline in market beta. As discussed previously, we use the absolute value of market beta as our dependent variable because non-proportional thinking should lead to stronger reactions to market news for lower-priced stocks, resulting in more positive betas for positive-beta stocks and more negative betas for negative-beta stocks. However, one may be concerned that stocks with measured betas in the negative range may simply be stocks where beta is measured with error. To show that this does not drive our results, Appendix Table A1 restricts the sample to observations with positive estimated market betas. We continue to find similar results in this subsample.

In Figure 2, we explore the shape of the price-volatility relation, without imposing a linear loglog structure. In Panel A, we plot the coefficients of a regression of volatility on 20 lagged share price bin indicators, with each bin containing the same number of observations, controlling for 20 size category bins and year-month fixed effects. All plotted coefficients measure the difference in volatility within each share price bin relative to the omitted bin of 20 (the largest share price). In Panel B, we plot the coefficients of a regression of volatility on 20 lagged share price bin indicators, this time with each bin representing an equal range of logged prices, again controlling for size and time fixed effects. The omitted category represents log lagged share price in the range of 5.0 to 5.25. In both flexible specifications, we observe a strong monotonic negative relation between volatility and share price. These figures show that our findings of a negative relation between volatility and nominal share price are unlikely to be driven by a few outlier observations. Rather, the negative relation holds between any two adjacent nominal price bins, and holds even in the range of high nominal share prices. Panel B also shows that the relation between the logarithm of volatility and the logarithm of share price is approximately linear, with a slight decrease in the absolute slope for 
very high-priced stocks. Thus, Panel B supports our use of a simple log-linear model as a reasonable way to represent the data in a parsimonious manner.

Our baseline analysis uses panel data at the stock-year-month level and exploits both crosssectional and time-series variation. To show that our findings are not caused by biases in the potential misspecification of time series or panel regressions, we can alternatively estimate the pure cross-sectional relation between volatility and lagged price within each month in our sample, i.e., a Fama-MacBeth style analysis. We estimate Equation 5, controlling for size category fixed effects, separately for each of the 1085 calendar year-months in our sample. Figure 3 plots the histogram of $\beta_{1}$, as estimated from 1085 cross-sectional regressions. The mean of the estimated coefficients is -0.31 , with a standard deviation of 0.10 , and almost all estimates are negative. Thus, we find a similarly-sized and robust negative volatility-price relation using only cross-sectional variation.

\subsubsection{Size Doesn't Matter (Much)}

The empirical patterns shown so far are consistent with non-proportional thinking. However, an omitted factor could determine both price and volatility. Our results can already reject one key alternative explanation involving size: It is well-known in the asset pricing literature that small-cap stocks (i.e., stocks with low market capitalization) tend to have higher return volatility, idiosyncratic volatility, and market beta. Since small-cap stocks also tend to have low nominal share prices (see Appendix Table A2 for correlations), size may simultaneously determine share price and volatility.

However, we showed in Tables 2 and 3 that the coefficient on lagged share price remains stable in magnitude and significant after controlling for the logarithm of lagged market capitalization or after controlling flexibly for size with 20 size category indicators. We also see in columns (2) and (3) of each table that, while size negatively predicts volatility if we do not control for price, the size-volatility relation flattens toward zero once we control for lagged nominal share price.

As an alternative way of illustrating these results, we note that size is equal to the product of price and shares outstanding. Therefore, we can examine whether the negative volatility-size relation is driven by price or shares outstanding, by regressing volatility on lagged price and lagged shares. Appendix Table A3 shows that the negative volatility-size relation is driven by price rather 
than shares outstanding.

We explore the relation between size and volatility in more detail in Figure 4. Panel A shows the coefficients from a regression of log total volatility (left) or log market beta (right) on 20 size category indicators (the largest size category is the omitted one), after controlling for year-month fixed effects. As expected, we find a strong negative relation between size and volatility and a strong negative relation between size and beta. In Panel B, we report the same set of coefficients for the 20 size indicators, after adding a single control variable for the log of the lagged nominal share price to the regression. We see that the relation between size and volatility, and size and beta, flattens dramatically. In the range between size categories 4 and 20, size continues to negatively predict volatility and beta. However, the magnitude of the slope shrinks by more than 80 percent. $^{8}$ These results cast doubt on the notion that size is a fundamental determinant of risk, as measured by volatility or market beta. Rather, a significant portion of the well-known size-volatility and size-beta empirical relations is driven by share price, in a manner consistent with non-proportional thinking.

\subsubsection{The Leverage Effect Puzzle}

A large body of research in asset pricing has explored the leverage effect puzzle, which refers to the strong negative relation between volatility and past returns in stock market data (e.g., Black, 1976). The phenomenon is named after a potential explanation involving leverage: holding debt levels constant, negative returns imply that the equity is more levered, leading to increased equity volatility (e.g., Christie, 1982). However, some have pointed out that the leverage-based explanation may be incomplete because the negative volatility-return relation is equally strong for firms with zero book leverage (e.g., Hasanhodzic and Lo, 2011), and others have offered non-leverage-based explanations (e.g., Campbell and Hentschel, 1992).

In this paper, we do not seek to reject any of the existing explanations of the leverage effect puzzle. Instead, we propose a model of non-proportional thinking as a new and potentially complementary explanation. Negative past returns imply a drop in share price, and a lower share price

\footnotetext{
${ }^{8}$ In the range of size categories 1 through 4 , the relation between beta and size is positive after controlling for price. However, beta may be measured with more error for these micro-cap stocks.
} 
causes an increase in volatility if investors engage in non-proportional thinking.

In Table 4, Panel A, we present regressions of volatility in the current month on past returns and share price, controlling for firm size categories and year-month fixed effects. First, in column (1) we repeat our baseline specification, limiting the sample to stock-year-months where returns over the previous 12 months are non-missing. In column (2), we replace lagged price with returns over the previous 12 months. We find that volatility is indeed strongly negatively related to past returns, with a coefficient of -0.24 on the measure of past returns. However, when we add a control for the lagged share price at the end of the previous month in column (3), the coefficient on past returns falls in absolute magnitude to -0.03. Further, the coefficient on lagged price (after controlling for past returns) remains stable in magnitude at approximately -0.33 . In other words, the coefficient on past returns falls by $87 \%$ in absolute magnitude once we add an additional control variable for price. Conversely, the coefficient on lagged price falls by a negligible $2 \%$ once we add a control variable for past returns. These results show that a large portion of the negative volatility-return relation may actually be driven by the correlation between past returns and share price. We also find similar patterns if we control for past returns separately for each the previous 12 months as in column (4). Altogether, these results show that, while price is correlated with past returns (see Appendix Table A2 for correlations), the price level is a stronger determinant of volatility. Controlling for the price level, it matters less how the stock arrived at that level, either through negative past returns or positive past returns.

One may still be concerned that our findings are driven by a negative relation between price and leverage, and a positive effect of leverage on equity volatility. To further rule out this possibility, in Table 4, Panel B, we limit the sample to stocks associated with firms with zero debt (current liabilities + long term debt) reported in their most recent quarterly financial statements. We continue to find similar results in this subsample. ${ }^{9}$

\footnotetext{
${ }^{9}$ We acknowledge that firms with zero debt may still have operating leverage, which may increase the risk of equity. It is not the goal of this paper to show that leverage cannot contribute to a leverage effect. Rather, we argue that a substantial portion of the leverage effect can be explained by non-proportional thinking.
} 


\subsubsection{Robustness and Heterogeneity}

\section{Additional Controls}

In Table 5, we repeat our baseline analysis including additional control variables that could affect volatility. In column (1), we begin by including minimal controls, as in column (1) of Table 2 Panel A. In column (2), we control for size even more thoroughly and flexibly than before by controlling for both the logarithm of lagged market capitalization as well as the 20 size category indicator variables and all interactions between the two. Using these flexible size controls, we continue to estimate a similar coefficient on price. In column (3), we add an additional control for lagged sales volatility which is a proxy for the fundamental volatility of each firm. This is measured as the standard deviation of year-over-year quarterly sales growth in the four most recently completed quarters. In column (4), we include a control for the stock's market-to-book ratio. In column (5) we control for volume turnover $\left(\frac{\text { Share Volume }}{\text { Shares Outstanding }}\right)$ and bid-ask spread percentage $\left(100 \times \frac{A s k-B i d}{A s k}\right)$. In column (6), we control for leverage $\left(\frac{\text { Current Liabilities }+ \text { Long Term Debt }}{\text { Book Assets }}\right)$. In all columns, we only include observations where all controls are non-missing so as to keep the sample consistent. While we estimate significant coefficients on many of these control variables, suggesting that they are indeed related to volatility, their inclusion has little effect on the estimated price coefficient. Therefore, our results do not, for example, appear to be driven by lower-priced stocks having higher fundamental sales volatility or lower liquidity.

\section{Tick Size}

A tick is the minimum unit for the price movement for a financial security. Tick size as a fraction of share price is larger for stocks with lower nominal share price, which may artificially inflate the measured volatility of lower-priced stocks.

In Figure 2, described previously, we found that the negative price-volatility relation holds even in the range of very high nominal share price bins, when tick size limits should have minimal impact. We will also show in Appendix Table A5 that the absolute magnitude of the price-volatility relation does not display a downward trend over time, even though tick sizes have fallen dramatically in 
recent decades. ${ }^{10}$

To further ensure that our results are not driven by tick sizes being large relative to prices for lower-priced stocks, in Table 6 we check that our results are robust to linear measures of volatility, which have been shown to be insensitive to tick sizes (Hau, 2006). Intuitively, with linear measures, rounding errors leading to artificially large price movements are canceled out by rounding errors leading to artificially small price movements on average. We find similar results when using such linear measures. Specifically, we measure volatility as (1) the mean intraday price range percentage $\left(100 \times \frac{\text { High-Low }}{\text { High }}\right)$ over all trading days in a stock-month, $(2)$ the mean absolute deviation $(|\operatorname{Ret}-\overline{\operatorname{Ret}}|)$ over all trading days in stock-month, and (3) the mean absolute return $(|\operatorname{Ret}|)$ over all trading days in a stock-month. We continue to estimate similar coefficients using these three measures of volatility. Therefore, our results do not appear to be driven by tick sizes being large relative to stock prices for low-priced stocks.

\section{Institutional Ownership}

Institutional investors may be more sophisticated than non-institutional investors and thus less likely to suffer from non-proportional thinking. If so, the price-volatility relation should be weaker for stocks with higher institutional ownership. To test whether this is the case, we repeat our baseline analysis, allowing the effect of price to interact with institutional ownership. ${ }^{11}$ The results are shown in Table 7. Consistent with the idea that institutional investors are more sophisticated, we estimate that volatility declines with price less when a stock has higher institutional ownership. A linear extrapolation implies that, as a stock moves from $0 \%$ institutional ownership to $100 \%$, the effect of price on volatility is reduced by approximately $44 \%$.

This analysis also partially addresses another potential alternative explanation, which is that lower-priced stocks may be held by unsophisticated noise traders or speculators who generate high volatility for reasons unrelated to non-proportional thinking. Table 7 shows that, indeed, stocks are

\footnotetext{
${ }^{10}$ Tick sizes moved from $1 / 8$ to $1 / 16$ in 1997 and from $1 / 16$ to 0.01 in 2001.

${ }^{11}$ As is standard in the literature, we define institutional ownership as the percent of outstanding shares reported to be held by institutions in quarterly $13 \mathrm{f}$ filings. The institutional ownership variable is updated quarterly, while our observations are at the monthly level. As before, we double-cluster standard errors by stock as well as yearmonth. The stock clustering should address the mechanical serial correlation in institutional ownership induced by the quarterly updating (as well as any other source of serial correlation in the error term of a given stock over time).
} 
more volatile when held by more unsophisticated investors. However, even among stocks with the same institutional ownership, lower-priced stocks are still more volatile.

\section{Size Subsamples}

While we have controlled for size to ensure that the estimated relation between price and volatility is not actually a size-volatility relation, we have not examined how the price-volatility relation varies with size. In Appendix Table A4, we repeat our baseline analysis in each of 20 size categories. As before, these size category bins come from Ken French's ME Breakpoints file. The breakpoints for a given month are based on the size distribution of stocks traded on the New York Stock Exchange in that month, with a breakpoint for every fifth percentile. Because our sample includes all stocks traded on the NYSE, AMEX, and NASDAQ exchanges, observations in our data are not equally distributed across the size categories.

As can be seen, our main finding is not a "micro-cap phenomenon" or even a "small-cap phenomenon." The negative relation between price and volatility continues to hold even among stocks in the top 5th percentile of the NYSE size distribution. Not surprisingly though, the magnitude of the volatility-price relation does decline with size, consistent with mispricing being less prevalent for large-cap stocks which may suffer less from limits to arbitrage.

\section{Time Period Subsamples}

In Appendix Table A5, we explore how the price-volatility relation has changed over time by repeating our baseline analysis in separate subsamples for each decade from the 1920s to the end of our sample period in 2016. We find that the coefficient is relatively stable across these different time periods and there are no secular trends. Thus, it does not seem that the relation has disappeared in recent years or is weakening over time. This also serves as additional evidence that tick size limitations do not drive our results, because tick sizes have declined over time. 


\section{Upside and Downside Volatility}

Non-proportional thinking predicts that higher share price leads to less extreme return responses to both positive and negative news. In Appendix Table A6, we show that share price is negatively related to both upside and downside volatility. Therefore, our results cannot be explained by other factors or anomalies that only affect one tail of returns. We measure upside (downside) volatility as the log of mean daily squared returns in each month conditional on the returns being positive (negative). We find that a doubling in share prices is associated with a greater than $30 \%$ decline in both upside and downside volatility. We can also measure upside (downside) market beta as the beta estimated using only days when the market return is positive (negative). We find that a doubling in share prices is associated with a greater than $30 \%$ decline in both upside and downside beta.

\subsection{Stock Splits}

Although we have controlled for many observable factors that could affect volatility, it remains possible that omitted variables may drive the negative relation between price and volatility. To better account for potential omitted factors, we study periods immediately surrounding stock splits. While stock splits are not completely randomly assigned across firms, the fundamentals of each firm are unlikely to change exactly on pre-announced stock split execution dates. ${ }^{12}$ Therefore, we can credibly attribute changes in volatility immediately after the split execution date to the change in share price.

\subsubsection{Daily Analysis}

We begin with granular daily stock return data to estimate a regression discontinuity around the date of the stock split. For the regression discontinuity, we change our measure of volatility from the standard deviation of daily returns within each calendar month to the intraday price range percentage $\left(100 \times \frac{\text { High-Low }}{\text { High }}\right) .{ }^{13}$ We omit the actual day of the split from the analysis, as it is not

\footnotetext{
${ }^{12}$ For a discussion of factors that may affect split decisions, see Weld et al. (2009) and Baker, Greenwood, and Wurgler (2009).

${ }^{13}$ In principle, one could also use intraday trading data from TAQ to address this question, but those data are only available for more recent years, and we see no reason that using such data would lead to different conclusions.
} 
clear whether the split takes place at the beginning of the trading day or the end. We begin by considering only 2 -for- 1 stock splits, in which one old share is converted to two new shares, as this is the most common type of split in the data.

In Figure 5, we non-parametrically estimate the intraday price range percentage in the 45 days before and after a split using local linear regression (with a triangular kernel and rule-of-thumb optimal bandwidth). ${ }^{14}$ We find that the intraday price range percentage increases by 1.4 immediately after the split. The jump in intraday price range percentage persists with a small decay over the next 40 trading days. Corresponding regression results are shown in Appendix Table A7. The magnitudes are very similar regardless of the kernel or bandwidth used.

\subsubsection{Monthly Analysis}

We also conduct event studies examining changes in total volatility, idiosyncratic volatility, and market beta around stock splits using monthly data. To explore how these measures of volatility change after splits, we estimate the following regression:

$$
\log \left(\operatorname{vol}_{i, t}\right)=\alpha+\sum_{k=-5}^{6} \beta_{k} \mathbb{1}\left(\text { EventMonth }_{i, t}=k\right)+\tau_{t}+\nu_{i}+\epsilon_{i, t}
$$

where $\mathbb{1}\left(\right.$ EventMont $\left._{i, t}=k\right)$ are indicator variables equal to one if month $t$ is $k$ months before or after a split month for stock $i, \tau_{t}$ are calendar year-month fixed effects, and $\nu_{i}$ are stock fixed effects. Observations are at the stock-month level, and the sample is limited to the six months before and after a split. The coefficients $\beta_{k}$ measure the difference in volatility in event month $k$ relative to month $t-6$, the omitted category. ${ }^{15}$ We again consider 2 -for-1 splits in which one old share is converted into two new shares.

We find that volatility (total volatility, idiosyncratic volatility, and market beta) rises significantly after stock splits. These patterns for total volatility and market beta are shown graphically

\footnotetext{
${ }^{14}$ We limit the sample to splits that are neither preceded by another split (for the same stock) in the previous 90 days, nor followed by another split in the subsequent 90 days, so that our estimation windows do not overlap with other splits.

${ }^{15}$ We limit the sample to splits that are neither preceded by another split (for the same stock) in the previous 12 months, nor followed by another split in the subsequent 12 months, so that our estimation windows do not overlap with other splits.
} 
in Figure 6. We plot the coefficients for each month in event time, relative to the omitted category of 6 months prior to the split. We omit the split month from these figures, as split months contain both pre-split and post-split days. We find that there is a slight pre-trend in that volatility rises in the six months leading up to the split, consistent with the view that splits are not entirely random. Firms choose to engage in stock splits following periods of good performance, which may coincide with a gradual increase in volatility. However, the direction and magnitude of the pre-trend cannot explain the sudden large and persistent jump in volatility after the split. In Appendix Table A8, we show the results in tabular format. The table also shows that we find similar jumps in idiosyncratic volatility after stock splits.

The estimated magnitude of the change in volatility following splits approximately matches the magnitudes from our baseline regressions using the full sample in Table 2. In our baseline analysis, we estimated that a doubling or halving of share price corresponds to an approximate $30 \%$ change in volatility. This is similar to the change in volatility following a 2 -for- 1 split, in which the share price falls by half.

\subsubsection{Heterogeneity by Type of Split}

In Figure 7, we compare the magnitude of the upward jump in volatility following stock splits by the type of split. The two most common types of splits in the data are 2 -for- 1 stock splits (in which the share price drops by 50\%) and 3-for- 2 stock splits (in which the share price drops by $33 \%$ ). Since 2-for-1 stock splits correspond to a bigger drop in share price, non-proportional thinking predicts a larger increase in volatility following a 2 -for- 1 split relative to a 3 -for- 2 split. This prediction matches the pattern in the data. In Panel A, we show that the pre-trends in volatility in the six months preceding the split are similar for the two types of stocks. After a 2-for-1split, stocks exhibit a significantly larger upward jump in volatility than after a 3-for-2 split. The fact that the magnitude of the jump in volatility can be cleanly ranked by the type of split also goes against a story in which a similar unobserved fundamental shock drives all splits.

In Figure 7, Panel B, we explore jumps in volatility following reverse stock splits, in which the number of shares drops sharply and the share price increases. Because reverse splits are relatively 
uncommon, we pool them all together in this case, regardless of how many shares are converted to one. Non-proportional thinking predicts that volatility will decline following reverse stock splits because the nominal share price increases. Consistent with this prediction, we find that volatility drops by more than 20 percent in the month following a reverse splits and the drop remains persistent over the next 6 months. As with regular splits, we observe a positive pre-trend in volatility in the months leading up to the split, suggesting that reverse splits follow periods of increasing volatility. However, the direction and small absolute magnitude of the pre-trend in volatility cannot explain the sudden and persistent drop in volatility following the reverse split.

Note that there is a gradual decrease in volatility in the months after a regular split (when share prices drop). At first, this may seem to suggest that investors eventually adjust to the new price

level and volatility moves back down toward its pre-split level. However, we also find that volatility gradually decreases in the months after a reverse split (when share prices rise). If investors were adjusting to the new price level, volatility should gradually increase after a reverse split. The fact that volatility seems to gradually increase before and gradually decrease after both types of splits instead suggests that splits tend to occur after a period of rising volatility, which is then followed by a period of declining volatility, all else equal. Regardless, these gradual trends are small relative to the large discontinuous jump in volatility immediately following the split execution date.

\subsubsection{Addressing Remaining Alternative Explanations}

A potential alternative explanation for our results is that splits, and lower share prices in general, may draw a less sophisticated investor base, which may directly increase volatility (Dhar, Goetzmann, and Zhu, 2004). A change to the investor base is unlikely to explain our results for four reasons. First, simple models of noise traders predict higher volatility (e.g., Brandt et al. (2009) and Foucault, Sraer, and Thesmar (2011)), but not necessarily greater sensitivity to market news. However, we find a large increase in market beta following splits in Appendix Table A8, which is consistent with non-proportional thinking leading to greater sensitivity to aggregate news for lower-priced stocks.

Second, speculation should lead to increased volume turnover $\left(\frac{\text { ShareVolume }}{\text { Shares Outstanding }}\right)$ following a 
split. Instead, we find in Figure 8 that there is a sharp and persistent decline in volume turnover following splits, with the opposite pattern for reverse splits. This change in volume is instead consistent with the view that some investors naively trade a fixed number of shares for each stock, e.g., 100 shares. Following a split, the share float doubles, so the number of shares traded relative to the float will decline after splits, and vice versa for reverse splits.

Third, we can directly check for changes in the investor base after 2-for-1 splits. We find that splits do indeed correspond to a small shift toward a less sophisticated investor base, but the change is much too small to account for the large jump in volatility that we document. In Table 8, we compare institutional ownership before a split (based on the last observed $13 \mathrm{f}$ filing leading up to the split) and after a split (based on the first observed $13 \mathrm{f}$ filing following the split). We find that institutional ownership declines very slightly (from $47.3 \%$ to $46.3 \%$ ) and the decline is not statistically significant. In Figure 9, we use data from Odean (1998) and Barber and Odean (2000), to examine changes in the characteristics of stocks' retail investors around splits. We find that the average annual income of retail investors holding a stock around a split event falls by less than $\$ 1000$ after the split, a difference that is statistically insignificant and economically small relative to the mean income level of $\$ 76.6 \mathrm{~K}$ prior to the split. Panel B shows that the number of retail investors who own a stock does jump slightly around the split execution data, but the jump is very small relative to overall upward time trend in retail ownership that begins well before the split execution date. Moreover, it is implausible that a $1 \%$ decline in institutional ownership and a small shift in retail ownership would account for a $30 \%$ jump in volatility. For comparison, Foucault, Sraer, and Thesmar (2011) exploit a natural experiment in France, to estimate changes in volatility caused by a much larger shock to retail investor trading activity. They find that an approximate $50 \%$ drop in retail trading activity caused only an $8.3 \%$ decline in a stock's volatility. ${ }^{16}$

Fourth, a speculative investor explanation is harder to square with the results in Figure 7, which show that the magnitude of the jump in volatility following splits can be cleanly sorted by the type of the split, 2-for-1 or 3-for-2.

\footnotetext{
${ }^{16}$ Foucault, Sraer, and Thesmar (2011) estimate that the reform led to an approximate $50 \%$ decline in the number of retail trades, and a 20 basis point decline in their measure of volatility (Volatility2) relative to a mean of 241 basis points (corresponding to an $8.3 \%$ decline).
} 
Another potential alternative explanation is that splits draw increased media attention, which may lead to increased volatility. However, the change in volatility after a split persists for many months, so it is unlikely to be caused by a temporary increase in media coverage. Further, investor attention should also increase following reverse splits which also receive significant media coverage. However, we find in Figure 7, Panel B, that volatility declines following these reverse stock splits, consistent with a non-proportional thinking model.

One may also be concerned that splits are timed in a way that coincides with fundamental changes in firm volatility. We believe that it is unlikely that firm fundamentals would change exactly on the pre-announced split execution date. We also directly check for changes in fundamental volatility. In Table 8, we compare mean sales volatility before a split (based on the last four quarters leading up to the split) and after a split (based on the first four quarters following the split), and find no significant differences.

Another potential explanation relates to changes in liquidity after a split which may affect volatility. As just discussed, we find that volume turnover declines after a split, which is inconsistent with a rise in speculative activity. However, a decline in volume turnover may indicate reduced liquidity. In the Appendix Table A9, we show again that volume turnover declines after splits and also bid-ask spread percentages increase. However, when we control for these measures of liquidity, we continue to observe a large increase in volatility around splits.

Finally, one may be concerned that the results relating to splits are driven by a handful of small-cap stocks. In Appendix Figures A1 and A2, we show that similar empirical patterns exist for intraday price range, total volatility, idiosyncratic volatility, market beta, and volume turnover for a subsample restricted to large-cap stocks in size categories 11 through 20 according to Ken French's market equity breakpoints.

\subsubsection{Option-Implied Volatility and a Trading Strategy}

We are also interested in the extent to which option traders anticipate the change in volatility following splits and how quickly they update their beliefs about volatility after the split. If option traders are very sophisticated, we expect that implied volatility (which reflects option traders' 
expectations of volatility over some future period) should increase prior to a split execution date, as splits are announced in advance, typically by one month. While many of the splits in our sample either pre-date the OptionMetrics data or are associated with stocks with few traded options, we are able to obtain option data for 921 split events. Panel A of Figure 10 plots 30-day implied volatility and 30-day realized volatility around splits. ${ }^{17}$ Implied volatility is calculated as a linear combination of implied volatilities from call options with approximate 30-day maturities, and realized volatility represents the realized volatility over the same subsequent 30-day window. In unreported results, we find similar results using implied volatility estimated from data on put options. The figure shows that option traders partially anticipate an increase in volatility but undershoot by a substantial margin. After the split, the 30-day implied volatility remains below the 30-day realized volatility, and does not converge until approximately 100 trading days after the split execution date. This shows that option traders do not fully anticipate the change in volatility around splits, and they do not immediately change their beliefs after the split.

The difference in implied volatility and realized volatility following split events suggests a profitable trading strategy that would involve going long option straddles (equivalent to buying both a call and put option) prior to pre-announced split execution dates. Option straddles pay off when realized volatility exceeds implied volatility, which is what we observe in the data following stock splits. Panel B of Figure 10 plots the returns to a straddle trading strategy. Details of the trading strategy are described in the figure notes. We find that this simple strategy of going long straddles around split execution dates leads to an average 15 percent return (not annualized) over the subsequent 40 trading days.

Because OptionMetrics data is only available for larger and more liquid stocks, these results also show that our findings related to splits are not a small-cap phenomenon. Even for large-cap stocks with options data, realized volatility jumps up significantly around splits, and implied volatility also increases, albeit with a lag consistent with option traders reacting with a delay.

\footnotetext{
${ }^{17}$ The figure displays a cyclical pattern that repeats approximately every three months. We believe this pattern is driven by quarterly earnings announcements, which cause an increase in volatility and implied volatility. Splits are often pre-announced around the time of the earnings announcement and executed one month later. The figure also shows that, on average, implied volatility exceeds realized volatility. This is a general feature of options data and may be explained by investors demanding compensation for risk.
} 


\section{Results: Return Responses to News Events}

\subsection{News Events Identified through Textual Analysis}

So far, we have focused on testing the volatility predictions from a simple model of non-proportional thinking. The model also predicts that stock returns will be more responsive to news for lowerpriced firms. Our previous results showing a large jump in market beta after splits already shows that the returns of lower-priced firms are more responsive to aggregate news. In this section, we directly examine return responses to firm-specific news events.

We begin by analyzing data from Boudoukh et al. (2018), which identifies value-relevant news events for S\&P 500 firms by applying a machine learning algorithm to the text of articles from Dow Jones Newswire. Using these data, we estimate equations of the form:

$$
\log \left(\left|C A R_{i,[t-1, t+1]}\right|\right)=\beta_{0}+\beta_{1} \log \left(\text { price }_{i, t-2}\right)+\text { controls }+\tau_{m(t)}+\epsilon_{i, t},
$$

where $C A R_{i,[t-1, t+1]}$ represents the cumulative abnormal returns for stock $i$ around a news event on date $t$, price $_{i, t-2}$ represents the stock price immediately prior to the event window, and $\tau_{m(t)}$ represents year-month fixed effects. ${ }^{18}$ Note that Equation 7 is analogous to Equation 2, derived from the simple model in Section 2.

The results are shown in Table 9. Consistent with non-proportional thinking, we find that cumulative abnormal returns around days with firm-specific news events are significantly more extreme for lower-priced stocks. A doubling in share price is associated with a 20 to $30 \%$ decline in the absolute magnitude of the return response. The pattern is similar for news that can be categorized (the first two columns) and for other types of firm-specific news (the last two columns). ${ }^{19}$

Of course, it is possible that lower-priced stocks simply have more extreme news events. However, it is worth emphasizing that the sample used in this analysis only includes $\mathrm{S} \& \mathrm{P} 500$ firms, which represent the largest firms in the US economy. Among these firms, it seems plausible that the

\footnotetext{
${ }^{18}$ Abnormal returns are computed relative to the market model, where market betas are estimated based on returns from dates $t-150$ to $t-50$.

${ }^{19}$ Categories of news defined by Boudoukh et al. (2018) include Business Trends, CSR Brand, Capital Returns, Deals, Earnings Factors, Employment, Facility, Financial, Financing, Forecast, General, Investment, Legal, Mergers Es Acquisitions, Product, Ratings, Stock, and Stock Holdings.
} 
distribution of news events would be similar across levels of nominal price. This analysis using S\&P 500 firms again shows that our model predictions apply to the largest stocks in the US economy.

\subsection{Earnings Announcements}

Another important and easily identifiable source of firm-specific news comes from pre-scheduled quarterly earnings announcements. Therefore, we also estimate Equation 7 using earning announcements as the news events. The results are shown in Table 10, Panel A. We find that cumulative abnormal returns around days with earning announcements are also significantly more extreme for lower-priced stocks. The magnitudes are similar to those in Table 9 which focused on news identified through textual analysis. Of course, it is again possible that lower-priced stocks have more extreme news - in this case about earnings. For example, there may be less information available to forecast earnings for lower-priced stocks and earnings announcements may convey more new information as a result. However, as shown in Table 10, we find similar results after controlling for firm size and analyst coverage, which suggests that the forecastability of earnings does not drive the results.

Moreover, unlike for news identified through textual analysis, we observe the extremity of earnings news. Specifically, as described in Section 3, we compute standardized unexpected earnings (SUE) as a measure of the magnitude of an earnings surprise, given the distribution of analyst forecasts prior to the announcement. ${ }^{20}$ Because our measure of earnings surprises requires multiple recent analysts forecasts, it is only available for a subset of the earnings announcements from Panel A of Table 10. Within this sample, we test whether the return response to the same earnings surprise is greater for lower-priced stocks. Following the literature, we sort earning announcements each year into deciles based on their SUE. We also sort them each year into quintiles based on their pre-announcement prices (on $t=-2$ ). We continue to measure the return response to an earnings announcement using cumulative abnormal returns from the day before the announcement to the day after the announcement.

\footnotetext{
${ }^{20}$ We focus on earnings surprises rather than earnings levels as our measure of news because whether a given level of earnings is good or bad news depends on investor expectations prior to the announcement. Moreover, the financial press typically reports earnings announcement news in terms of how much earnings beat or missed expectations. Therefore, the earnings surprise is likely to be the measure of earnings news that is most salient to investors. Analysts are professionals who are paid to forecast future earnings. While there is some debate about how unbiased analysts are (e.g., Hong and Kubik, 2003 and So, 2013), our tests only require that such a bias is not correlated with the earnings surprise.
} 
In the first two columns of Table 10, Panel B, we regress the return response to an announcement on the SUE decile rank, its lagged price quintile, and all interactions. Instead of including 10 SUE decile indicators, we use a single decile rank variable for SUE in the regressions. This is in keeping with the literature and is primarily done for expositional clarity (we find qualitatively similar patterns using decile indicators). In column (1), we estimate a positive and statistically significant coefficient on the uninteracted SUE decile rank variable. The magnitude of the coefficient is approximately 0.01 . This means that for stocks in the lowest price quintile, each increase in SUE decile rank is associated with a $1 \%$ greater return response to an earnings announcement. The estimated coefficients on the interactions with the price quintile indicators are all negative and get increasingly negative with each price quintile. Summing coefficients, we see that an increase in SUE decile rank is still associated with a positive return response in each price quintile, but the return response is monotonically less positive the greater the stock's pre-announcement price. In the highest price quintile, the return response to an increase in SUE decile rank is roughly half that in the lowest price quintile. The results remain similar after controlling for size and analyst coverage in column (2). We also find similar patterns in the final two columns, where we examine how price interacts with the return response for top SUE decile announcements relative to bottom SUE decile announcements. Overall, these results indicate that return response to the same earnings surprise is greater for lower-priced stocks, which is what we would expect under non-proportional thinking.

\subsection{Reversals}

If investors overreact to news for low-priced stocks, we would expect these stocks to experience stronger subsequent reversals as prices return to fundamentals. Before proceeding to empirical tests of reversals, we first discuss two caveats. First, non-proportional thinking does not necessarily imply that low-priced stocks overreact to news in an absolute sense. Rather, non-proportional thinking only implies that low-priced stocks react more strongly to news relative to high-priced stocks. For example, it could be that, for unrelated reasons, all stocks underreact to news. In this case, lowpriced stocks would underreact less, and we would expect weaker subsequent drift for low-priced stocks relative to high-priced stocks. A second important caveat is that the existence of a return 
correction does not imply that the non-proportional thinking bias goes to zero in future periods. Even as the misreaction to previous news is corrected, investors can again under- or overreact to future news due to non-proportional thinking.

With these caveats in mind, we proceed to our empirical tests. De Bondt and Thaler (1985) show that stocks that experience extreme returns tend to experience subsequent reversals, suggesting that the market overreacts to news. We follow their methodology to examine whether the market is more likely to overreact to news for lower-priced stocks. Specifically, we first sort stocks in each year-month $t$ by past cumulative abnormal returns over the interval $[t-36, t-1]$. Our winners portfolio consists of all stocks in the top decile of past performance, and our losers portfolio consists of all stocks in the bottom decile of past performance. ${ }^{21}$ Like De Bondt and Thaler, we interpret stocks in these portfolios to have experienced extreme news. We then partition the winner and loser portfolios into quintiles in terms of lagged share price as of month $t-37$, which precedes the period used to categorize winners and losers. ${ }^{22}$

The cumulative abnormal returns to holding equal-weighted winner and loser portfolios in each lagged share price quintile are presented in Figure 11. We are able to replicate the original De Bondt and Thaler long-run reversal result with our updated data: the past winners portfolio experiences subsequent negative abnormal returns and the past losers portfolio experiences subsequent positive abnormal returns. More interestingly, we can sort the magnitude of the long-run reversal by lagged share price. We find that the lowest quintile of stocks in terms of lagged nominal share price corresponds to the most extreme outperformance among the past losers portfolio. Similarly, the lowest quintile of stocks by share price also corresponds to the most extreme underperformance among the past winners portfolio. Further, the magnitude of the long-run reversal within the past winners and past losers portfolios can almost perfectly be ordered by lagged share price (the only exception being price quintiles 3 and 5 in the winners portfolio, which are crossed). In general, as price increases, the absolute magnitude of the reversal decreases. These results are consistent with

\footnotetext{
${ }^{21}$ This sorting is more inclusive than the original De Bondt and Thaler (1985) which only focused on the extreme top 35 winner and loser stocks.

${ }^{22}$ We sort by price before the start of the past return evaluation window, so we do not induce an automatic correlation between our past performance sort and lagged price, which could occur if we instead used lagged price in month $t-1$.
} 
the idea that the market is more likely to overreact to news for lower-priced stocks, as we would expect under non-proportional thinking.

Finally, we show that the magnitude of the long-run reversal varies significantly with lagged price and substantially less so with lagged size. Table 11, columns (1)-(3), show regressions of future abnormal returns on past abnormal returns and the interaction between past abnormal returns and lagged price and/or size. The regressions also control for the direct effects of lagged price and size. To account for time variation in the level of returns, as well as time variation in the overall magnitude of the reversal phenomenon, we estimate this regression using the standard FamaMacBeth methodology in asset pricing. ${ }^{23}$ Lagged price and size are measured as of the end of month $t-37$. We find that the direct effect of past returns on future returns is negative, consistent with a long-run reversal. The interaction term in column (1) shows that the absolute magnitude of the reversal decreases significantly with lagged price. Column 2 shows that the reversal also decreases with lagged size. Most interestingly, column (3) shows that, when we allow the magnitude of the return reversal to vary with both price and size, we find that it is strongly related to price, and almost unrelated to size.

In columns (4)—(6), we find similar results when examining the reversal pattern in a shorter window, following the methods in Jegadeesh (1990). We continue to find in columns (4)—(6) that the magnitude of the short-run reversal is strongest for lower-priced stocks, and is more strongly related to lagged price than lagged size.

\section{Conclusion}

We hypothesize that investors in financial markets engage in non-proportional thinking — they think that news should correspond to a dollar change in price rather than a percentage change in price, leading to more extreme return responses to news for lower-priced stocks. Consistent with a simple model of non-proportional thinking, we find that total volatility, idiosyncratic volatility, and market beta are significantly higher for stocks with lower share prices. To identify a causal effect of price,

\footnotetext{
${ }^{23}$ This is equivalent to estimating a cross-sectional regression for each time period, and reporting the simple average of the coefficients across time periods. This approach is similar to allowing for a time period fixed effect and time fixed effects interacted with all explanatory variables, and reporting the average coefficients across time.
} 
we show that volatility increases sharply following stock splits and drops following reverse stock splits. Further, non-proportional thinking leads to more extreme return responses to news identified through textual analysis or earnings announcements for lower-priced stocks. The economic magnitudes are large: a doubling in a stock's nominal price is associated with a $20-30 \%$ decline in its volatility, beta, and return response to firm-specific news.

Our analysis sheds light on the determinants of volatility in financial markets. We show that non-proportional thinking is an important determinant of cross-sectional variation in volatility. Well-known asset pricing patterns such as the leverage effect and the negative relation between size and risk (volatility or beta) can be reinterpreted through the lens of non-proportional thinking. Our analysis also offers a new explanation of over- and underreaction to news and subsequent reversals/drift. The existing behavioral finance literature has mainly focused on limited attention or belief errors regarding the persistence of news shocks to explain these patterns. Non-proportional thinking offers a complementary explanation: over and under-reaction to news and consequent reversals/drift can also be caused by investors thinking in the wrong units.

Our findings also offer a new perspective on the evidence in psychology documenting proportional thinking. This literature has focused on cases in which consumers should think in levels, but mistakenly think in proportions. By examining behavior in a financial setting, we show that investors also suffer from non-proportional thinking. Our results are suggestive of a broader view that people may think partially in proportions and partially in levels, leading to potentially costly mistakes in settings in which they should think entirely in one frame or the other. 


\section{References}

Azar, Ofer H, 2007, Relative thinking theory, Journal of Socio-Economics 36, 1-14.

Baker, Malcolm, Robin Greenwood, and Jeffrey Wurgler, 2009, Catering through nominal share prices, Journal of Finance 64, 2559-2590.

Baker, Malcolm, Stefan Nagel, and Jeffrey Wurgler, 2007, The effect of dividends on consumption, Brookings Papers on Economic Activity 2007, 231-291.

Baker, Malcolm and Jeffrey Wurgler, 2004a, Appearing and disappearing dividends: The link to catering incentives, Journal of Financial Economics 73, 271-288.

Baker, Malcolm and Jeffrey Wurgler, 2004b, A catering theory of dividends, Journal of Finance 59, 1125-1165.

Barber, Brad M and Terrance Odean, 2000, Trading is hazardous to your wealth: The common stock investment performance of individual investors, Journal of Finance 55, 773-806.

Barber, Brad M and Terrance Odean, 2001, Boys will be boys: Gender, overconfidence, and common stock investment, Quarterly Journal of Economics 116, 261-292.

Barberis, Nicholas, Andrei Shleifer, and Robert Vishny, 1998, A model of investor sentiment, Journal of Financial Economics 49, 307-343.

Benartzi, Shlomo and Richard H. Thaler, 1995, Myopic loss aversion and the equity premium puzzle, Quarterly Journal of Economics 110, 73-92.

Birru, Justin and Baolian Wang, 2015, The nominal price premium, Working Paper (Ohio State University).

Birru, Justin and Baolian Wang, 2016, Nominal price illusion, Journal of Financial Economics 119, $578-598$.

Black, Fischer, 1976, Studies of stock price volatility changes, Proceedings of the Business and Economics Section of the American Statistical Association 177-181.

Boudoukh, Jacob, Ronen Feldman, Shimon Kogan, and Matthew Richardson, 2018, Information, trading, and volatility: Evidence from firm-specific news, Review of Financial Studies 32, 9921033 .

Brandt, Michael W, Alon Brav, John R Graham, and Alok Kumar, 2009, The idiosyncratic volatility puzzle: Time trend or speculative episodes?, Review of Financial Studies 23, 863-899.

Bushong, Benjamin, Matthew Rabin, and Joshua Schwartzstein, 2015, A model of relative thinking, Working Paper (Michigan State University).

Campbell, John Y. and Ludger Hentschel, 1992, No news is good news: An asymmetric model of changing volatility in stock returns, Journal of Financial Economics 31, $281-318$.

Christie, Andrew A., 1982, The stochastic behavior of common stock variances: Value, leverage and interest rate effects, Journal of Financial Economics 10, 407 - 432. 
De Bondt, Werner FM and Richard Thaler, 1985, Does the stock market overreact?, Journal of Finance 40, 793-805.

Dhar, Ravi, William N Goetzmann, and Ning Zhu, 2004, The impact of clientele changes: Evidence from stock splits, Working Paper (Yale University).

Dimson, Elroy, 1979, Risk measurement when shares are subject to infrequent trading, Journal of Financial Economics 7, 197-226.

Fisher, Irving, 1928, The money illusion (Adelphi Company, New York, NY).

Foucault, Thierry, David Sraer, and David J Thesmar, 2011, Individual investors and volatility, Journal of Finance 66, 1369-1406.

Glosten, Lawrence R., Jagannathan Ravi, and David E. Runkle, 1993, On the relation between the expected value and the volatility of the nominal excess return on stocks, Journal of Finance 48, 1779-1801.

Greenwood, Robin and Andrei Shleifer, 2014, Expectations of returns and expected returns, Review of Financial Studies 27, 714-746.

Hartzmark, Samuel M and David H Solomon, 2017, The dividend disconnect, Working Paper (University of Chicago).

Hartzmark, Samuel M and David H Solomon, 2018, Reconsidering returns, Working Paper (University of Chicago).

Hasanhodzic, Jasmina and Andrew W. Lo, 2011, Black's leverage effect is not due to leverage, Working Paper (Babson College).

Hau, Harald, 2006, The role of transaction costs for financial volatility: Evidence from the Paris Bourse, Journal of the European Economic Association 4, 862-890.

Hirshleifer, David and Siew Hong Teoh, 2003, Limited attention, information disclosure, and financial reporting, Journal of Accounting and Economics 36, 337-386.

Hong, Harrison and Jeffrey D Kubik, 2003, Analyzing the analysts: Career concerns and biased earnings forecasts, Journal of Finance 313-351.

Hong, Harrison and Jeremy C Stein, 1999, A unified theory of underreaction, momentum trading, and overreaction in asset markets, Journal of Finance 54, 2143-2184.

Jegadeesh, Narasimhan, 1990, Evidence of predictable behavior of security returns, Journal of Finance 45, 881-898.

Jegadeesh, Narasimhan and Joshua Livnat, 2006, Post-earnings-announcement drift: The role of revenue surprises, Financial Analysts Journal 22-34.

Lakonishok, Josef, Andrei Shleifer, and Robert W Vishny, 1994, Contrarian investment, extrapolation, and risk, Journal of Finance 49, 1541-1578.

Lamont, Owen A and Richard H Thaler, 2003, Can the market add and subtract? Mispricing in tech stock carve-outs, Journal of Political Economy 111, 227-268. 
Lewellen, Jonathan and Stefan Nagel, 2006, The conditional CAPM does not explain asset-pricing anomalies, Journal of Financial Economics 82, 289-314.

Lian, Chen, Yueran Ma, and Carmen Wang, 2018, Low interest rates and risk taking: Evidence from individual investment decisions, Review of Financial Studies .

Mendenhall, Richard R, 2004, Arbitrage risk and post-earnings-announcement drift, Journal of Business 77, 875-894.

Modigliani, Franco and Richard A. Cohn, 1979, Inflation, rational valuation and the market, $F i$ nancial Analysts Journal 35, 24-44.

Odean, Terrance, 1998, Are investors reluctant to realize their losses?, Journal of Finance 53, 17751798.

Ohlson, James A and Stephen H Penman, 1985, Volatility increases subsequent to stock splits: An empirical aberration, Journal of Financial Economics 14, 251-266.

Pratt, John W, David A Wise, and Richard Zeckhauser, 1979, Price differences in almost competitive markets, The Quarterly Journal of Economics 93, 189-211.

Ritter, Jay R and Richard S Warr, 2002, The decline of inflation and the bull market of 1982-1999, Journal of Financial and Quantitative Analysis 37, 29-61.

Roger, Tristan, Patrick Roger, and Alain Schatt, 2018, Behavioral bias in number processing: Evidence from analysts' expectations, Journal of Economic Behavior 63 Organization 149, 315-331.

Shiller, Robert J., 1981, The use of volatility measures in assessing market efficiency, Journal of Finance 36, 291-304.

Shue, Kelly and Richard R. Townsend, 2017, Growth through rigidity: An explanation for the rise in CEO pay, Journal of Financial Economics 123, 1 - 21.

So, Eric C, 2013, A new approach to predicting analyst forecast errors: Do investors overweight analyst forecasts?, Journal of Financial Economics 108, 615-640.

Svedsäter, Henrik, Amelie Gamble, and Tommy Gärling, 2007, Money illusion in intuitive financial judgments: Influences of nominal representation of share prices, Journal of Socio-Economics 36, $698-712$

Thaler, Richard, 1980, Toward a positive theory of consumer choice, Journal of Economic Behavior \& Organization 1, 39-60.

Tversky, Amos and Daniel Kahneman, 1981, The framing of decisions and the psychology of choice, Science 211, 453-458.

Weld, William C, Roni Michaely, Richard H Thaler, and Shlomo Benartzi, 2009, The nominal share price puzzle, Journal of Economic Perspectives 23, 121-42. 
Figure 1

Display of Changes in the Value of Stocks

Panel A: Wall Street Journal, 1970

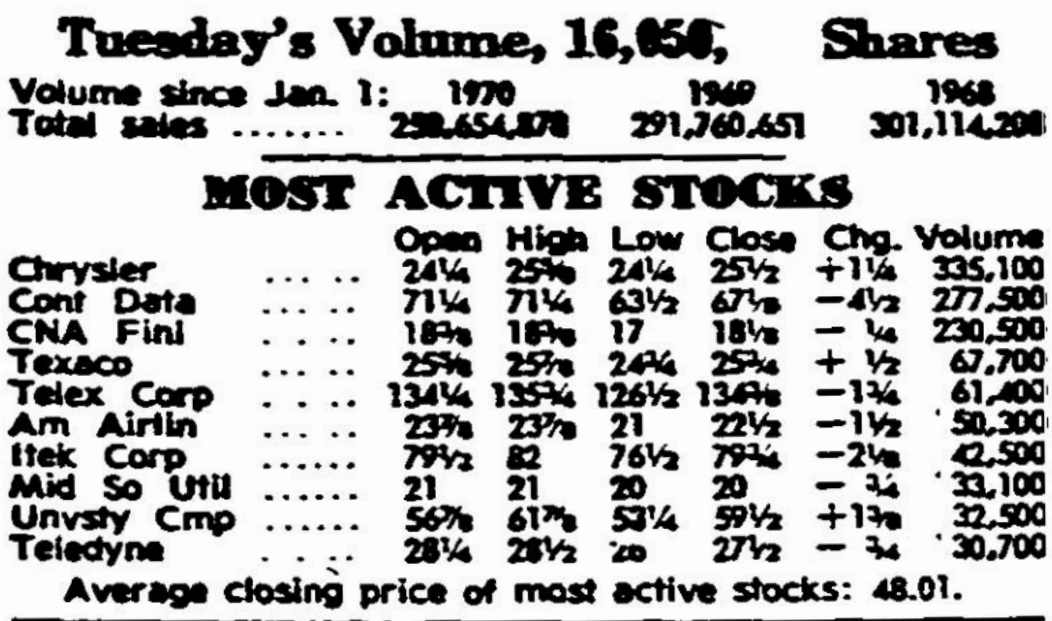

Panel B: Apple Stocks and Etrade Smartphone Apps, 2017

\begin{tabular}{|c|c|c|c|}
\hline \multicolumn{3}{|c|}{ AT\&T Wi-Fi ₹ $\quad$ 7:40 PM } & \\
\hline \multicolumn{2}{|c|}{ 000001.SS } & $3,480.83$ & -7.18 \\
\hline \multicolumn{2}{|c|}{ 399001.SZ } & $11,159.68$ & -119.11 \\
\hline \multicolumn{2}{|c|}{ AAPL } & 167.43 & +0.46 \\
\hline \multicolumn{2}{|c|}{ GOOG } & $1,169.94$ & +6.25 \\
\hline \multicolumn{2}{|c|}{ YHOO } & 0.00 & +0.00 \\
\hline \multicolumn{2}{|c|}{ DOW J } & $26,149.39$ & +72.50 \\
\hline \multicolumn{2}{|c|}{ FTSE 100} & $7,533.55$ & -54.43 \\
\hline \multicolumn{4}{|c|}{ Alphabet Inc. } \\
\hline OPEN & $1,170.57$ & MKT CAP & $817.0 \mathrm{~B}$ \\
\hline HIGH & $1,173.00$ & 52W HIGH & $1,186.89$ \\
\hline Low & $1,159.13$ & $52 W$ LOW & 791.19 \\
\hline vol & $1.539 \mathrm{M}$ & AVG VOL & $1.305 \mathrm{M}$ \\
\hline P/E & 39.10 & YIELD & - \\
\hline YAHOO! & & Kotcosed & $\vdots \equiv$ \\
\hline
\end{tabular}

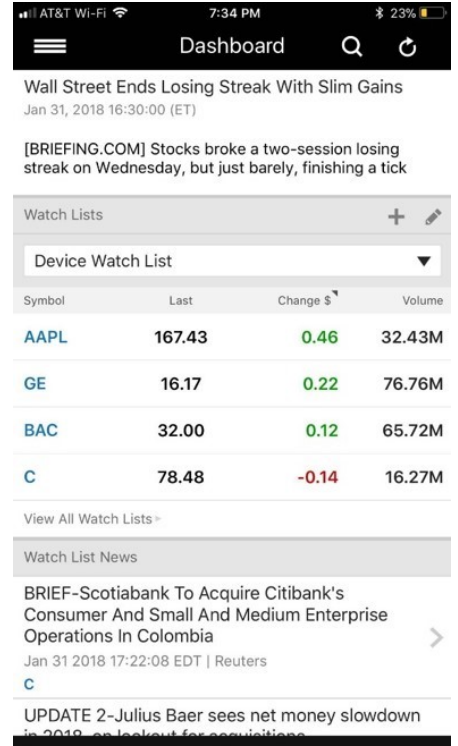

Panel C: CNBC Ticker, 2016

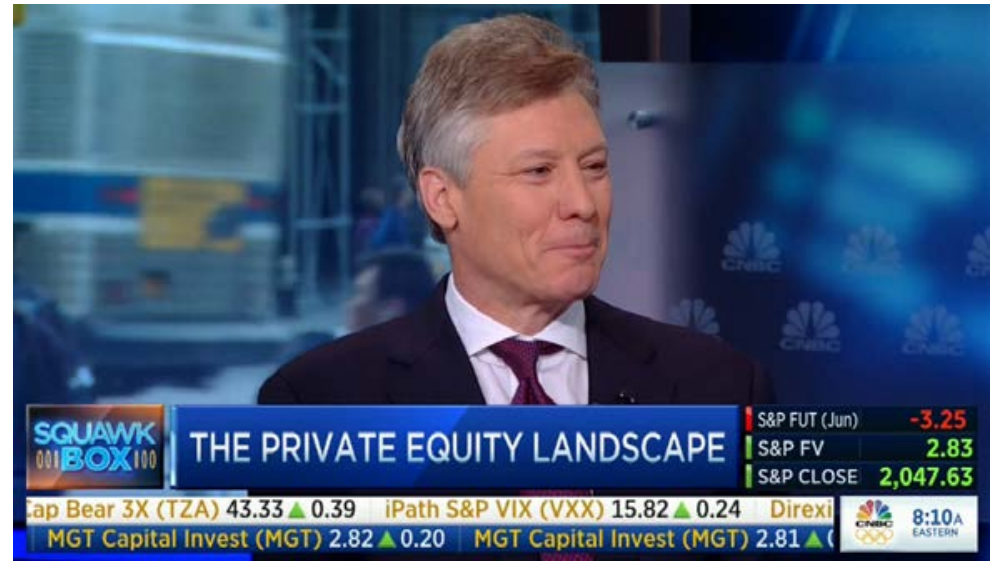


Figure 2

Shape of Volatility-Price Relation

Panel A of this figure shows the non-parametric shape of the volatility-price relation. It repeats the regression from Panel A of Table 2 column (4) which controls for size categories and year-month fixed effects, replacing the continuous $\log$ (Lagged Price) variable with 20 lagged share price bin indicators, with each bin containing the same number of observations. The resulting coefficients are plotted with vertical bars indicating $95 \%$ confidence intervals. Quantile 20 is omitted. Panel B repeats the analysis of Panel A, with the modification that each bin represents an equal range of logged prices, again controlling for size and time fixed effects. The omitted category represents log lagged share price in the range of 5.0 to 5.25. Standard errors are double-clustered by stock and year-month.

Panel A: Equally-Spaced Price Bins, Controlling for Size

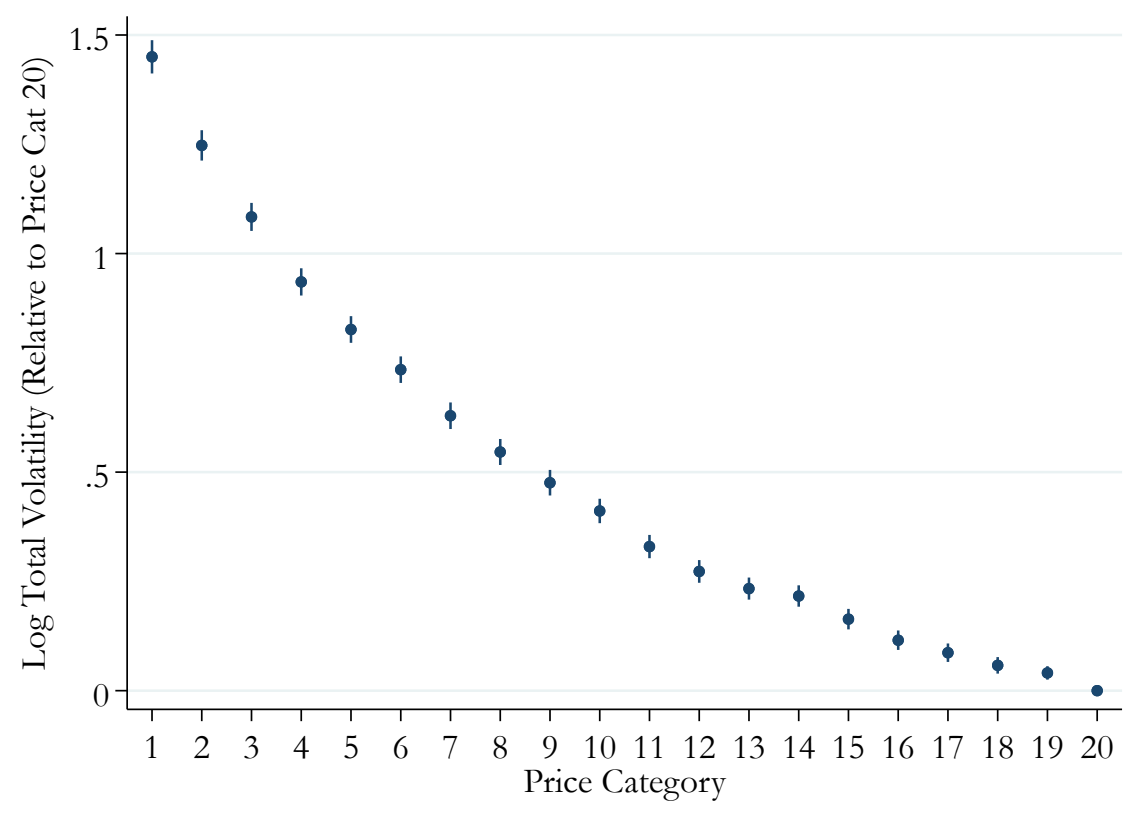

Panel B: Log-Log Volatility and Price Relation, Controlling for Size

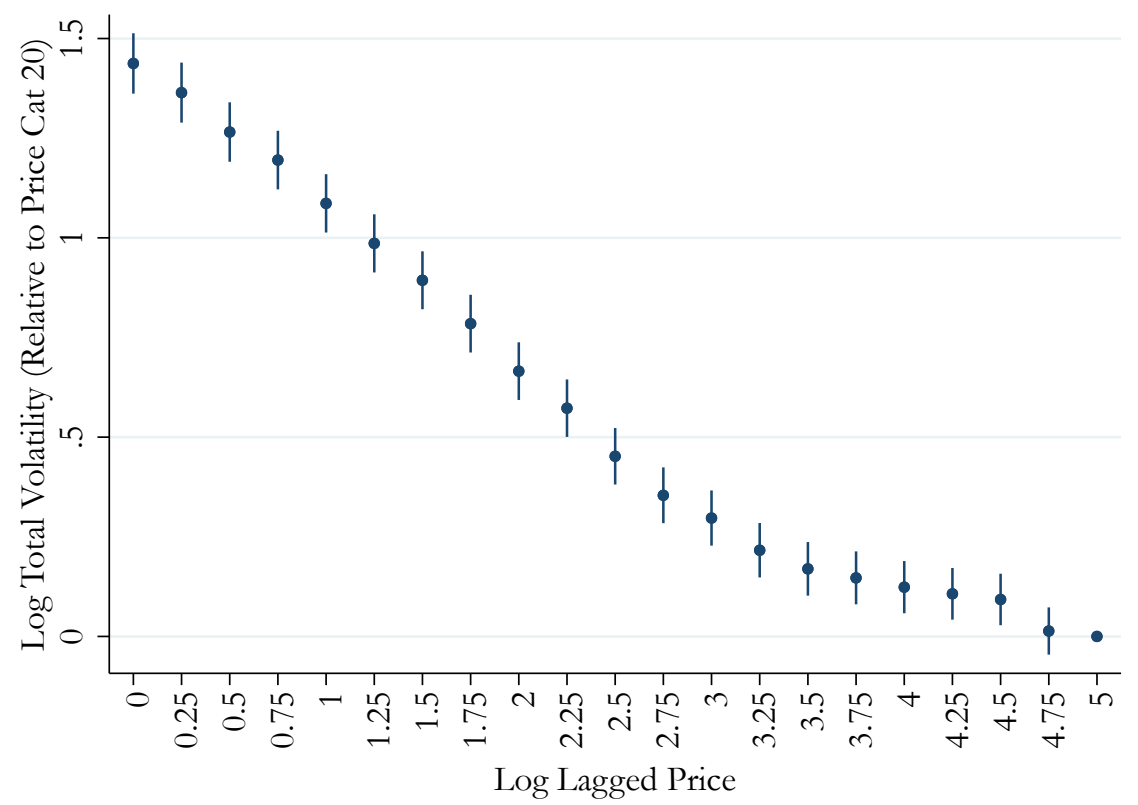


Figure 3

Cross-Sectional Estimation

For each of the 1,085 calendar year-months in our data sample, we estimate a cross-sectional regression of $\log$ volatility on lagged log price, controlling for 20 size categories. This figure plots a histogram of the estimated coefficients on lagged log price from the 1,085 regressions. The mean of the coefficients is -0.31 , and the standard deviation is 0.10 .

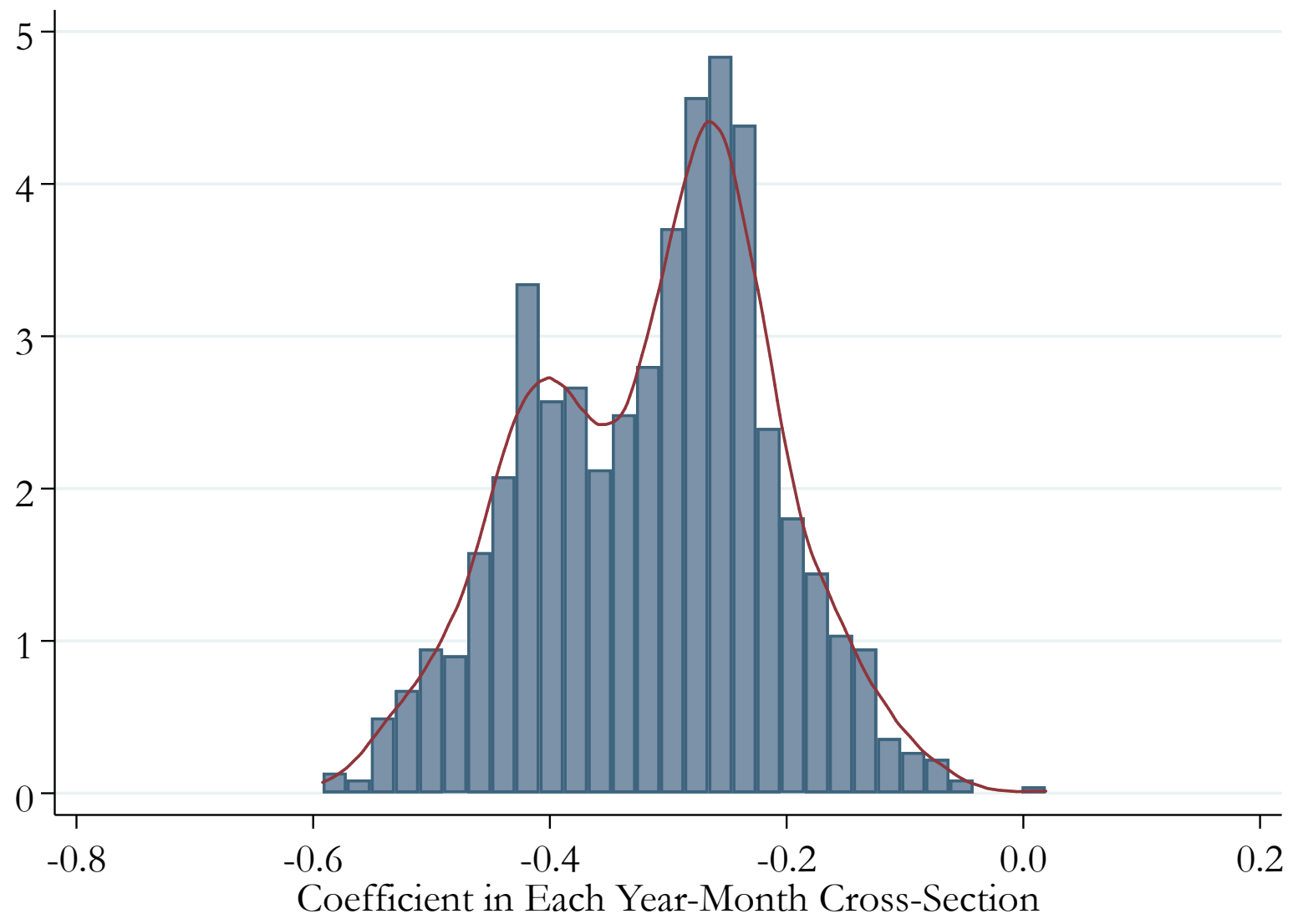




\section{Figure 4}

How Price Affects the Size-Volatility and Size-Beta Relations

This figure explores the extent to which nominal price differences explain the negative volatility-size and beta-size relations. Panel A shows the coefficients from a regression of log volatility or log absolute beta on 20 size category indicators (defined using the Fama French size category cutoffs in the corresponding year-month, with the largest size bin as the omitted category) as of the end of the previous month, after controlling for year-month fixed effects. Panel B shows the same set of coefficients after adding in a single additional control variable for the log of the lagged nominal share price. The dots represent the coefficient estimates and the vertical lines represent $95 \%$ confidence intervals. Standard errors are double-clustered by stock and year-month.

\section{Panel A: Size-Volatility and Size-Beta Relations, Without Controlling for Price}
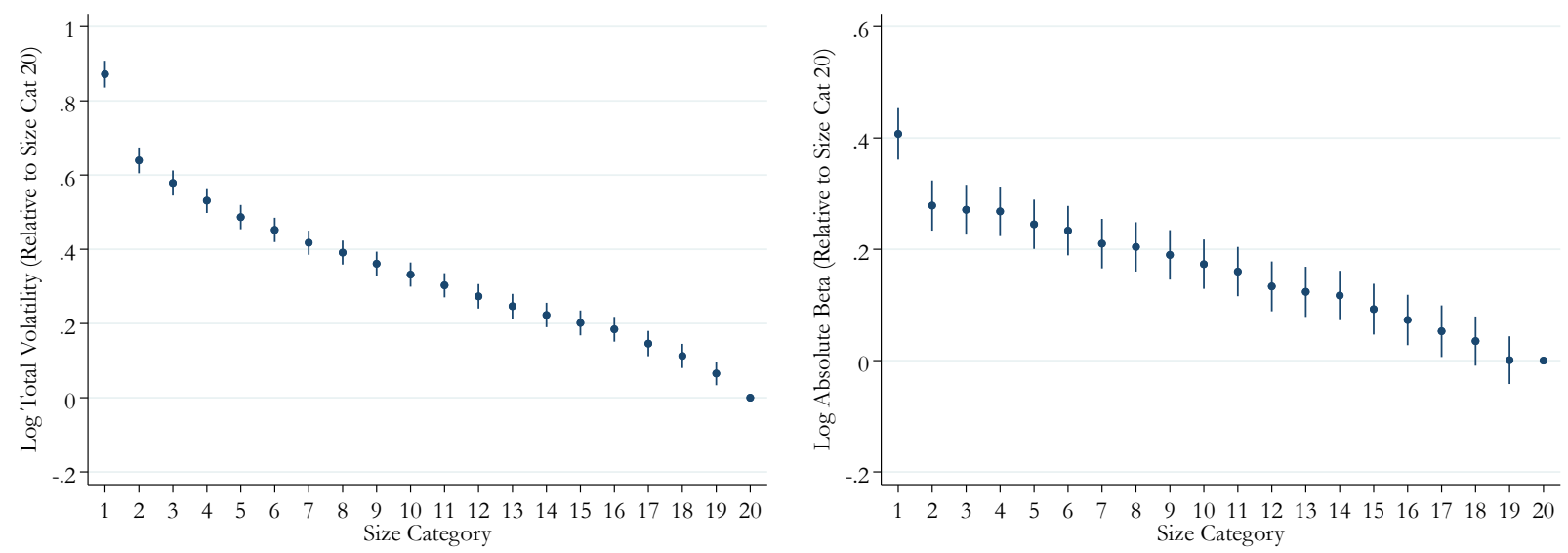

Panel B: Size-Volatility and Size-Beta Relations, Controlling for Price
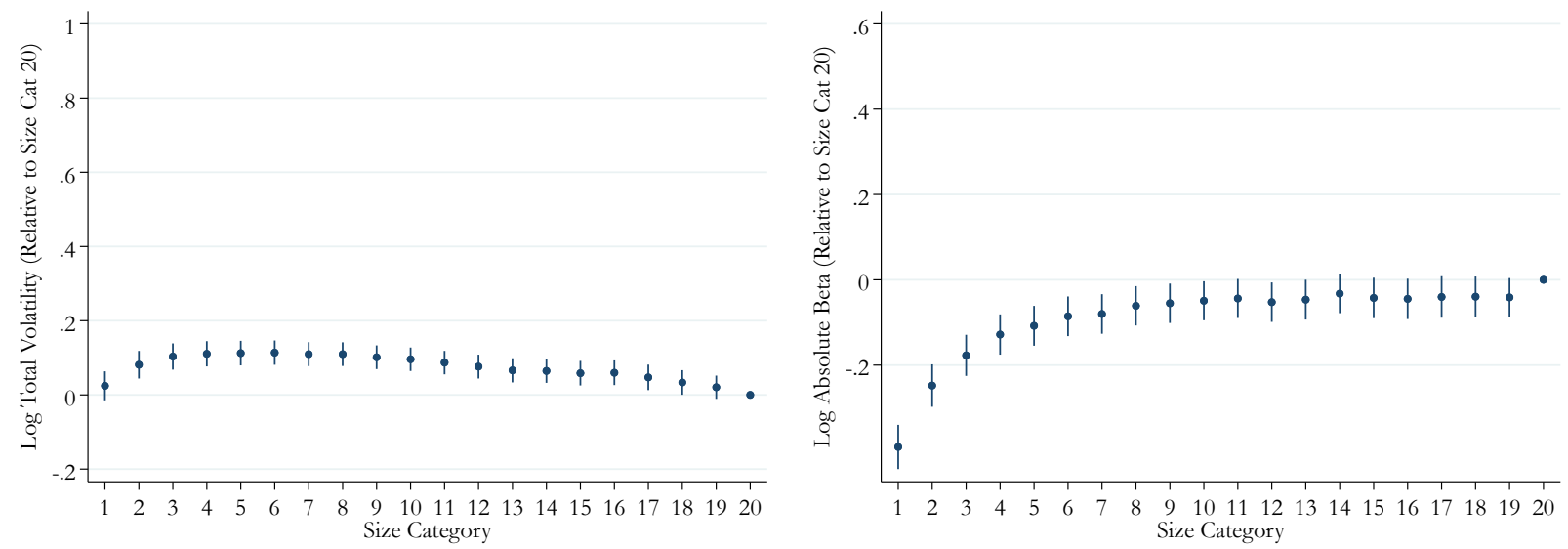
Figure 5

Regression Discontinuity: Intraday Price Range Around Stock Splits

This figure shows changes in volatility around 2-for-1 stock splits. It examines 45 days before and after the pre-announced split execution date. Volatility is proxied for by the intraday price range percentage, defined as $100 \times \frac{\text { High-Low }}{\text { High }}$. The day of the split execution event is excluded. The thick lines represent non-parametric estimates of the mean on a given day, estimated using a local linear regression with a triangular kernel and MSE-optimal bandwidth. The thin lines represent $95 \%$ confidence intervals. The dots show raw means for each event day.

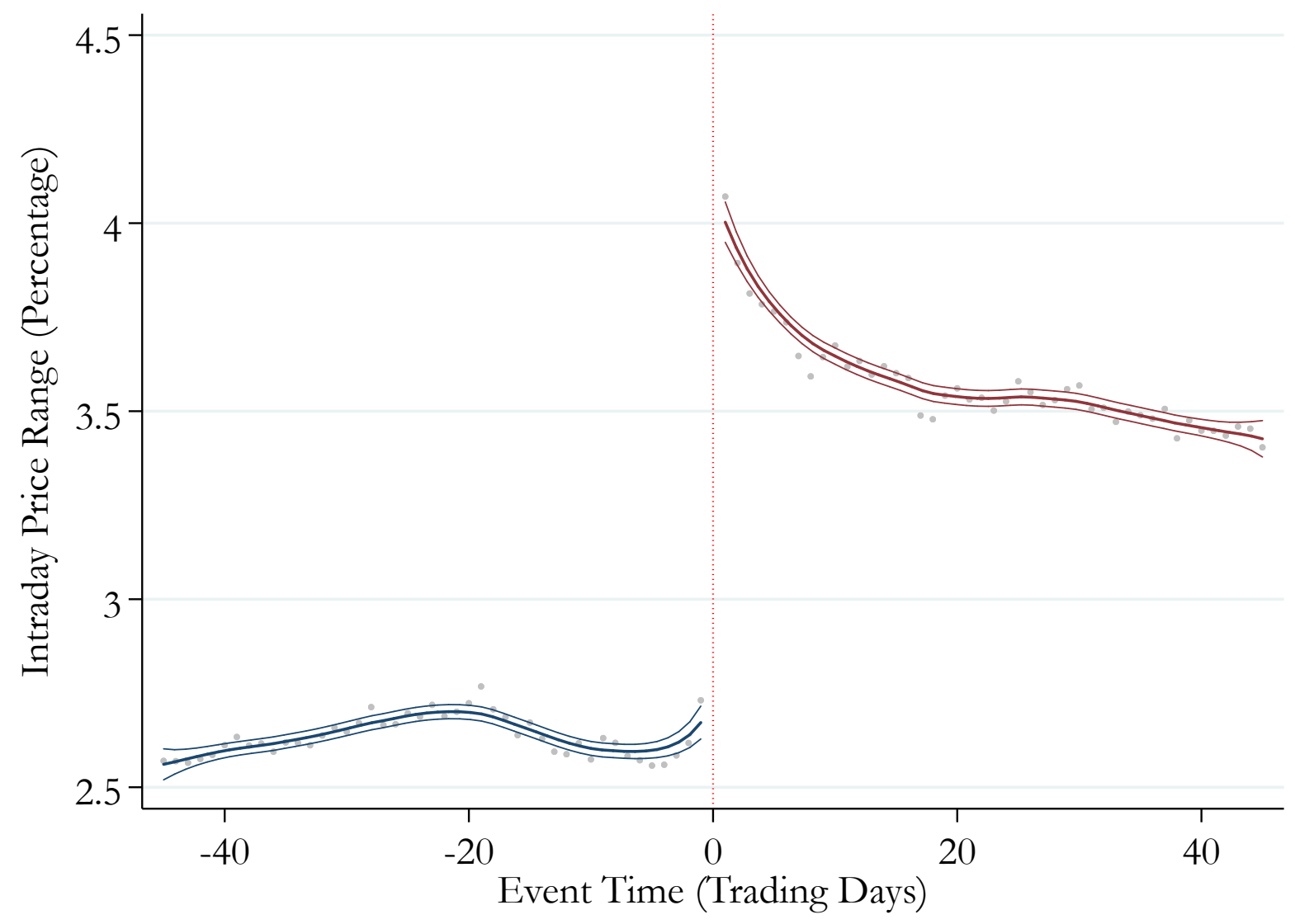


Figure 6

Event Study: Volatility and Beta Around Stock Splits

This figure show changes in total volatility (Panel A) and market beta (Panel B) in each event-month around 2 -for-1 stock splits. We estimate equations of the form:

$$
\log \left(\operatorname{vol}_{i, t}\right)=\alpha+\sum_{k=-5}^{6} \beta_{k} \mathbb{1}\left(\text { EventMonth }_{i, t}=k\right)+\tau_{t}+\nu_{i}+\epsilon_{i, t},
$$

where $\mathbb{1}\left(\right.$ EventMonth $\left._{i, t}=k\right)$ are indicator variables equal to one if month $t$ is $k$ months before or after a split month for stock $i, \tau_{t}$ are year-month fixed effects, and $\nu_{i}$ are stock fixed effects. Observations are at the stock-month level, and the sample is limited to the six months before and after a split. Event month -6 is the omitted category. The dots represent the point estimates for the $\beta_{k}$ coefficients and the vertical lines represent $95 \%$ confidence intervals. The coefficient on $\beta_{0}$ is not shown, since event month $k=0$ contains both pre-split and post-split days. Standard errors are double-clustered by stock and year-month.

\section{Panel A: Total Volatility}

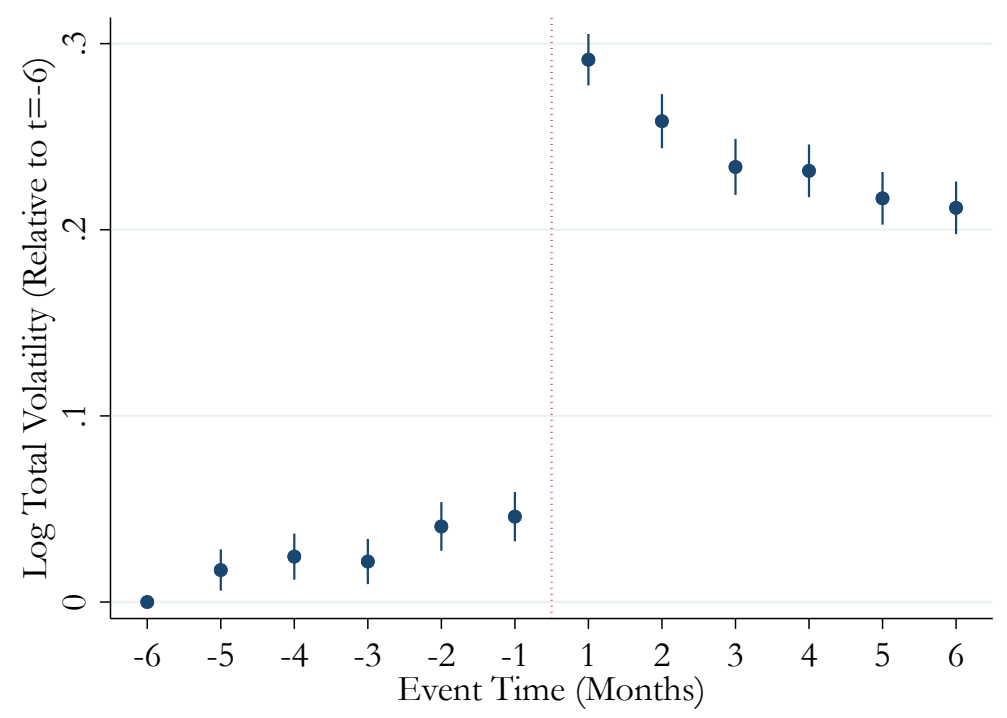

Panel B: Market Beta

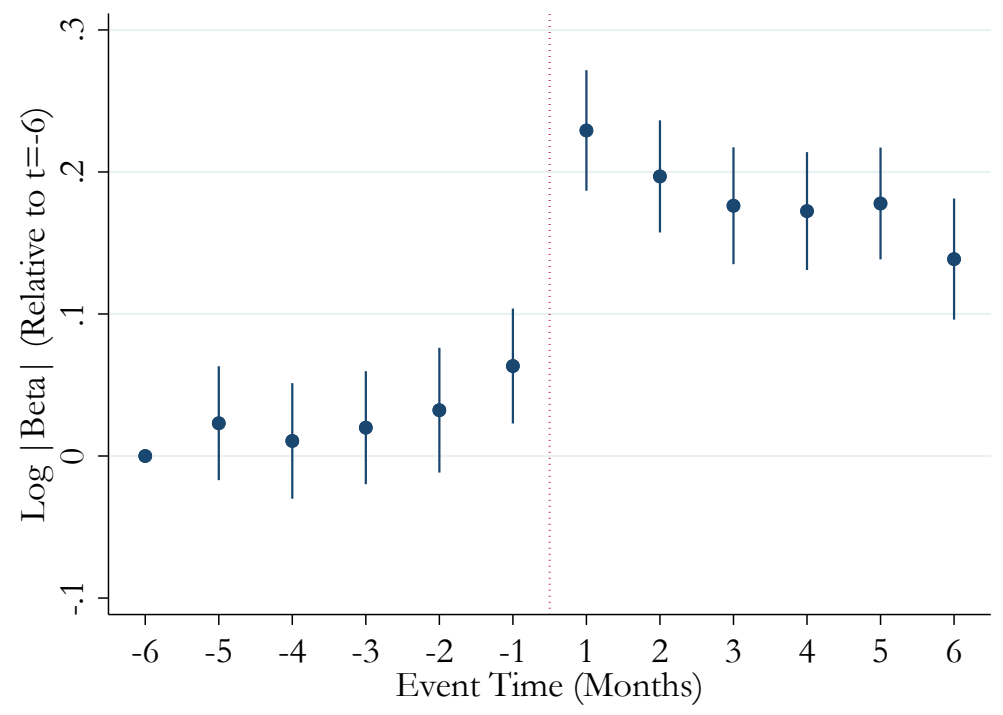




\section{Figure 7}

Comparison by Type of Split

Panel A of this figure shows volatility patterns around 3-for-2 stock splits alongside those around 2-for-1 stock splits. Panel B shows volatility patterns around reverse stock splits. Both panels are generated as described in Figure 6.

Panel A: Volatility, 2-for-1 Versus 3-for-2 Splits

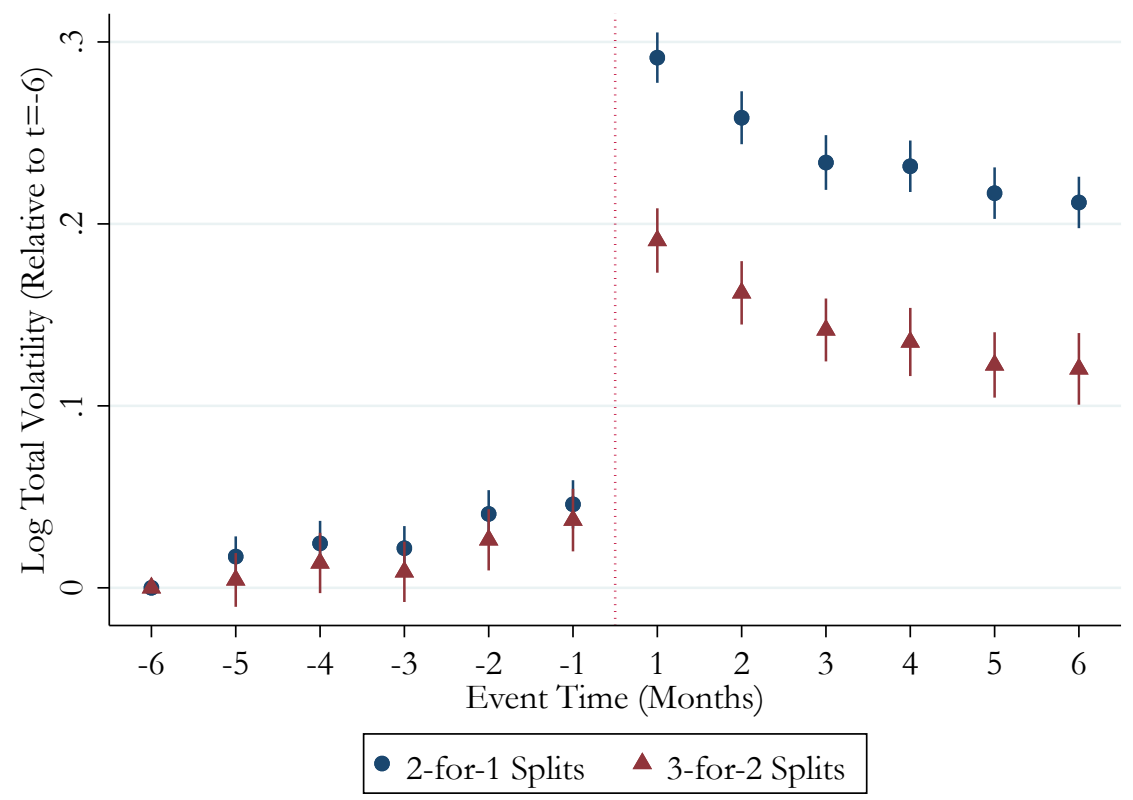

Panel B: Volatility, Reverse Splits

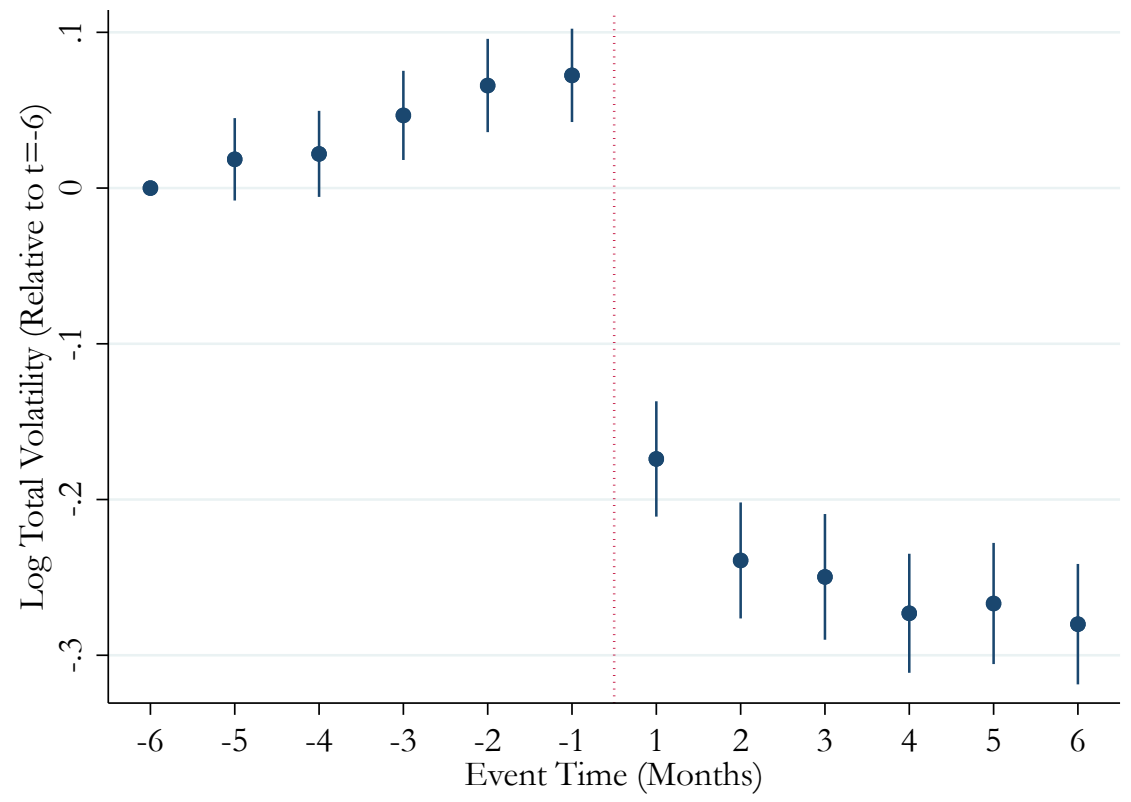




\section{Figure 8}

Event Study: Volume Around Stock Splits and Reverse Stock Splits

Panel A shows the pattern of volume around 2-for-1 stock splits. Panel B shows the pattern of volume around reverse stock splits. Volume turnover is defined as the number of shares traded in each month divided by the total number of shares outstanding. Both panels are generated as described in Figure 6.

\section{Panel A: Volume, Positive Stock Splits}

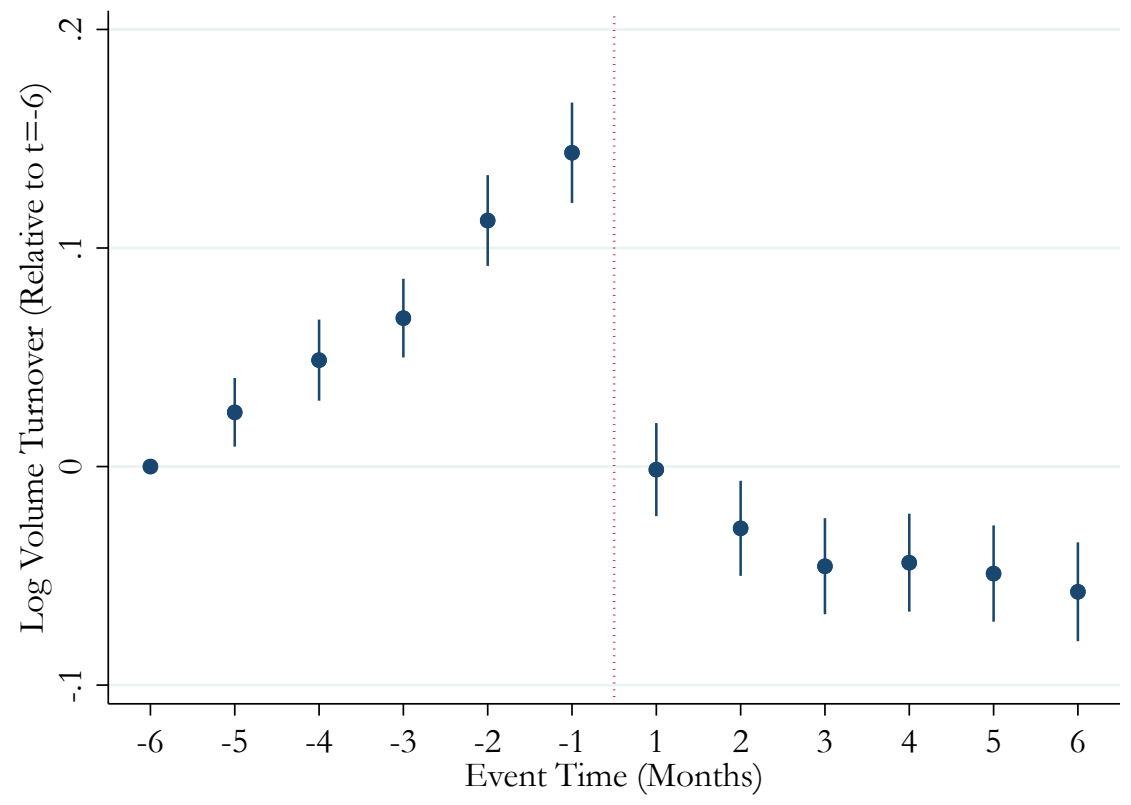

Panel B: Volume, Reverse Stock Splits

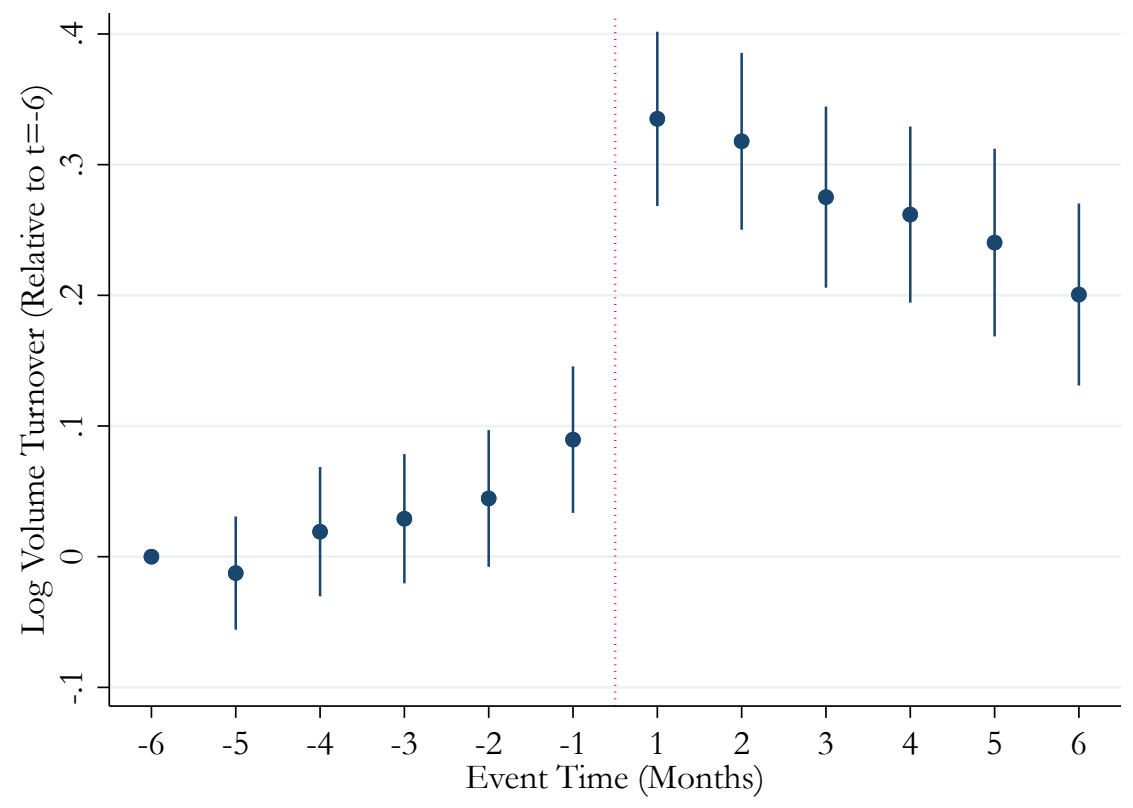




\section{Figure 9}

Retail Ownership Around Splits

This figure shows changes in retail ownership around 2-for-1 stock splits. The data comes from Odean (1998) and covers all retail trades for a large discount broker (LDB). The dots in Panel A show the mean income of associated LDB accounts that hold the stock around the split event. The inner lines in Panel A come from local linear regressions estimated with a 10-day bandwidth and triangular kernel. The outer lines represent $95 \%$ confidence intervals. The raw data provide income ranges rather than exact income. Following Barber and Odean (2001), we assign income according to the midpoint of an individual's income range. We classify individuals in the top income range $(>\$ 125,000)$ as having an income of $\$ 137,500$. The dots in Panel B show the mean number of LDB accounts that hold a stock around a split.

\section{Panel A: Income of Large Discount Broker Shareholders}

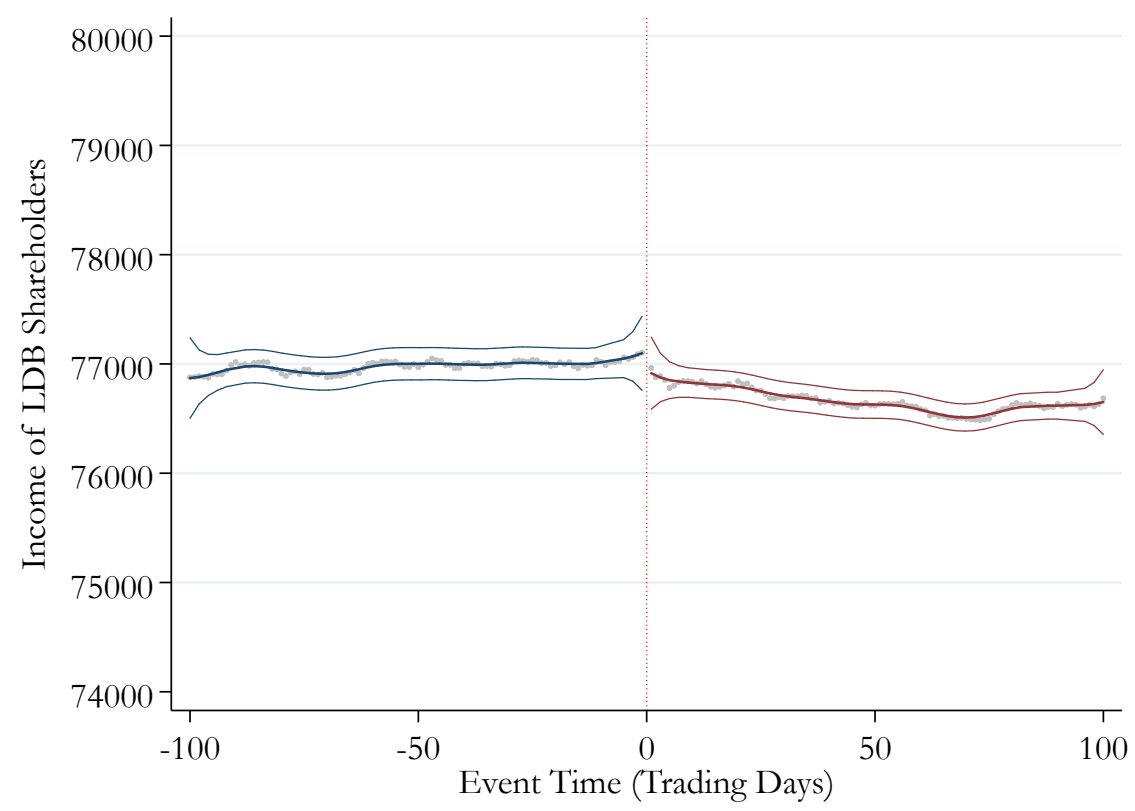

Panel B: Number of Large Discount Broker Shareholders

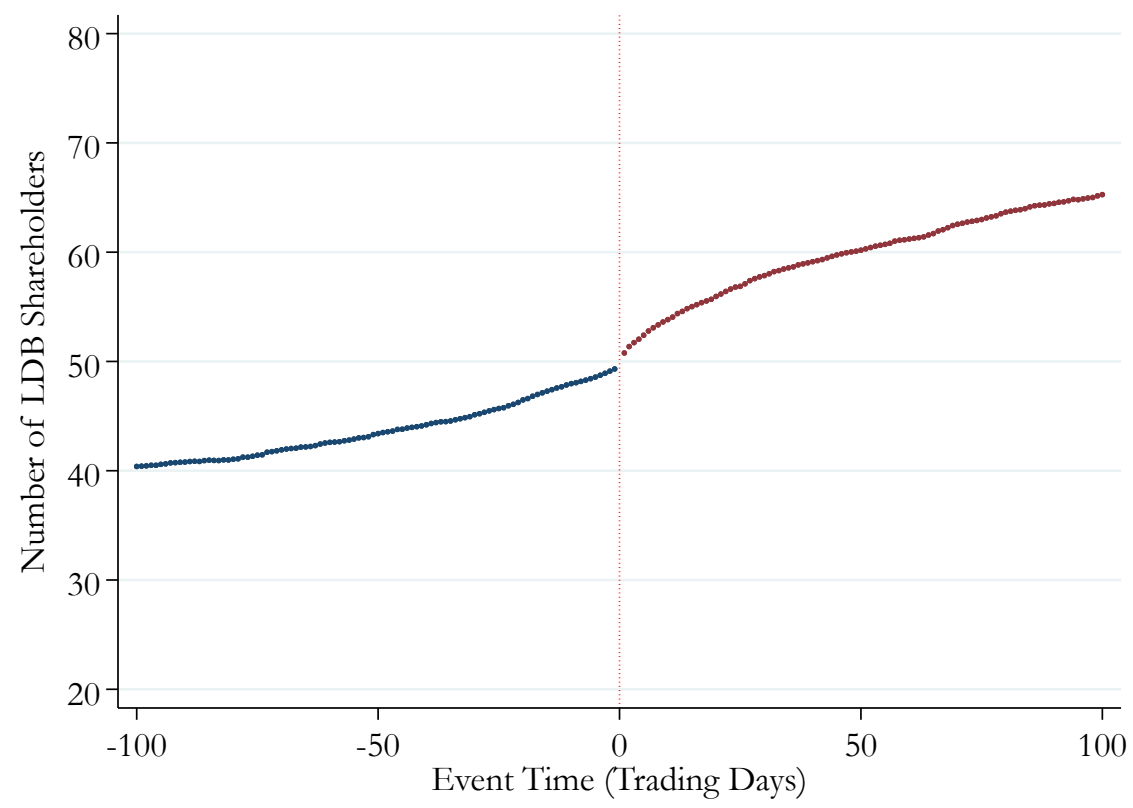




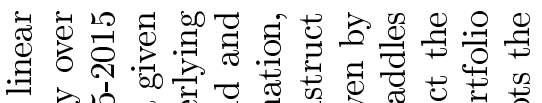

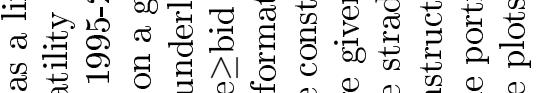

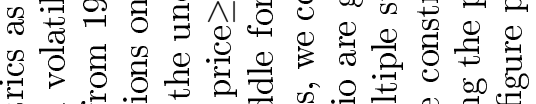

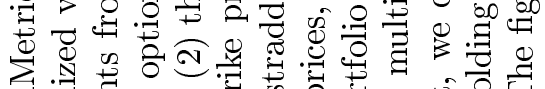

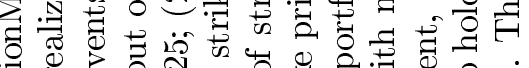

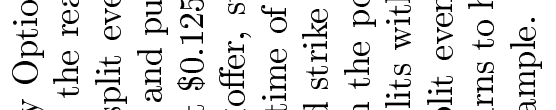

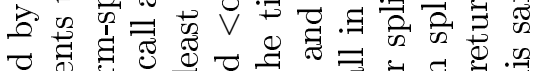

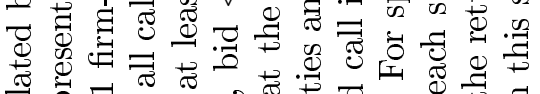

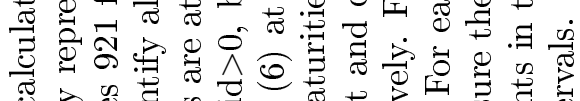

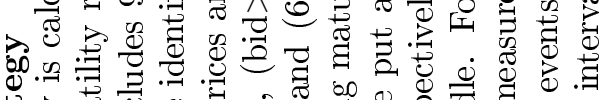

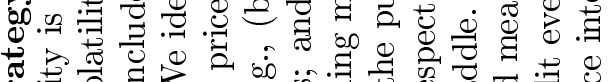

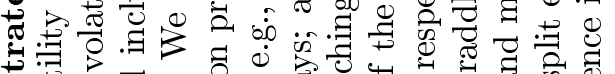
की

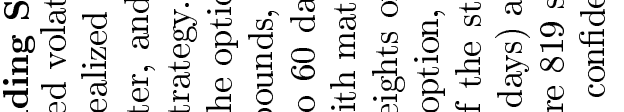

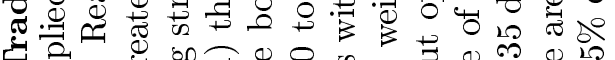

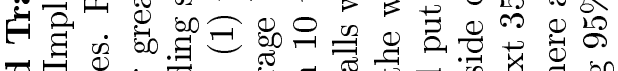
สี

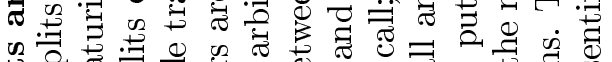

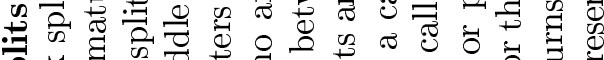
윽 की

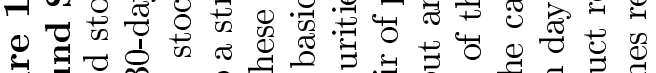
क力

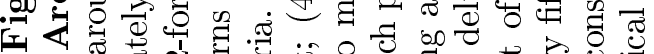

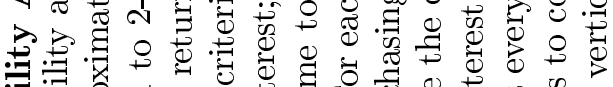

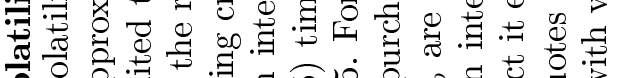

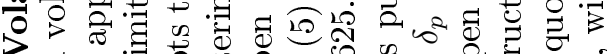

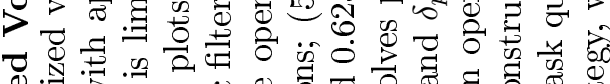

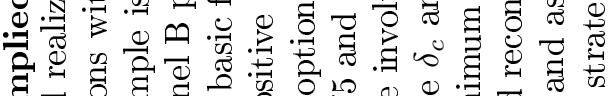

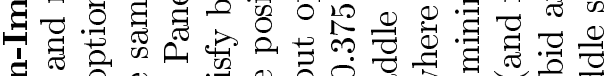

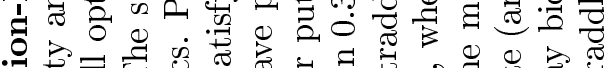

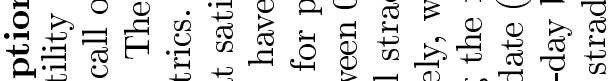

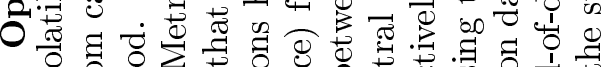

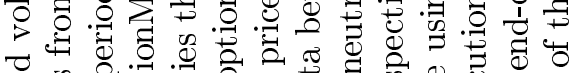

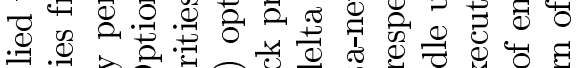

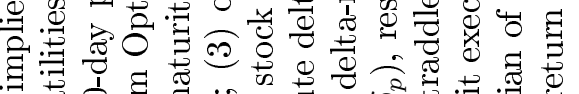

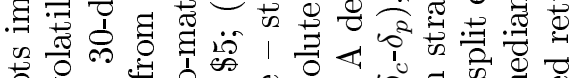

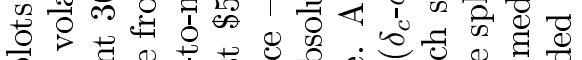

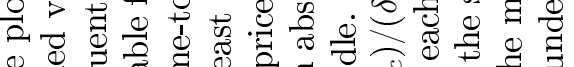

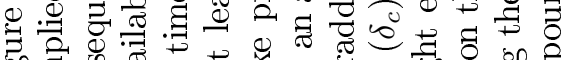

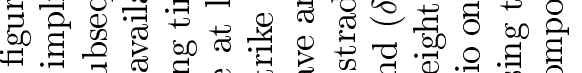

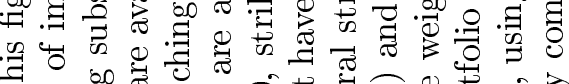

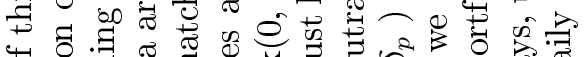

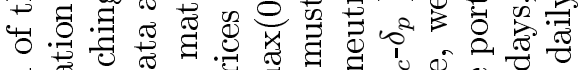

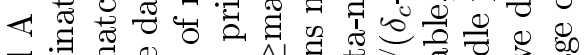

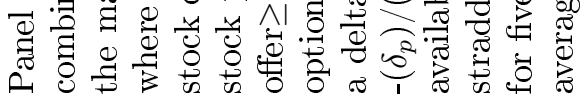
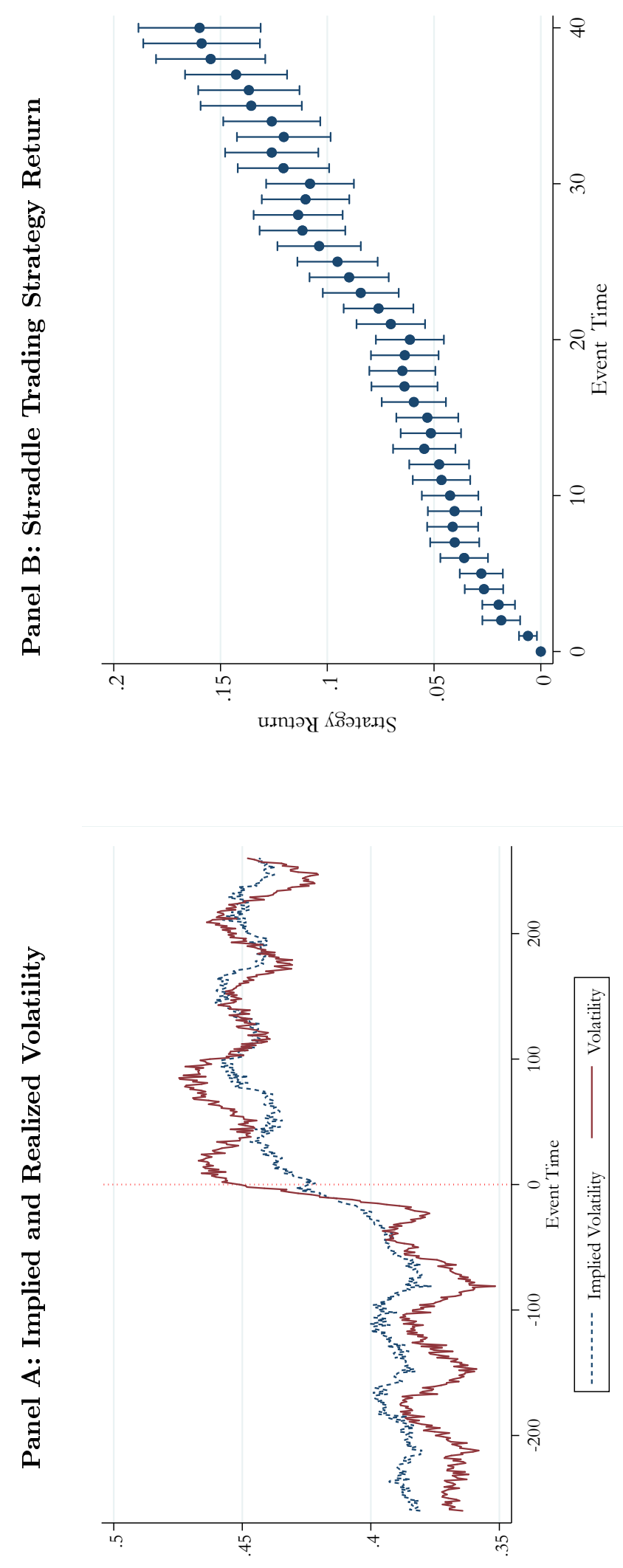


\section{Figure 11}

Long-Run Reversal, Sorted by Lagged Price

This figure plots cumulative abnormal returns to holding equal-weighted winner and loser portfolios in each lagged share price quintile. Stocks are first sorted in each year-month $t$ by past cumulative abnormal returns over the interval $[t-36, t-1]$. The winners portfolio consists of all stocks in the top decile of past performance, and the losers portfolio consists of all stocks in the bottom decile of past performance. The winner and loser portfolios are then partitioned into quintiles in terms of lagged share price as of month $t-37$, which precedes the period used to categorize winners and losers. Past performance and subsequent cumulative abnormal returns are measured using market-adjusted returns as in De Bondt and Thaler (1985).

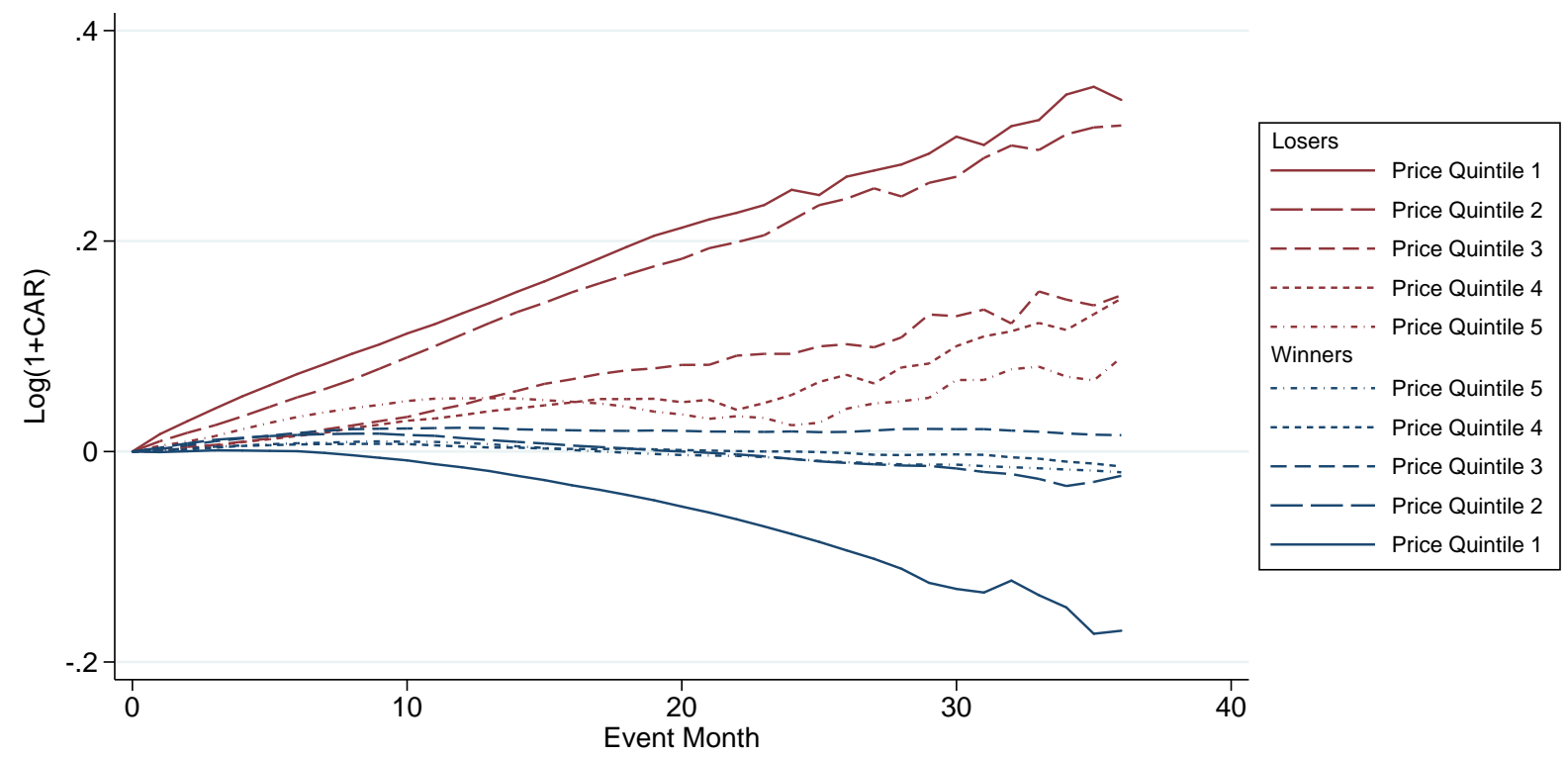


Table 1

\section{Summary Statistics}

This table summarizes the variables used in our analyses. Observations are at the stock-month level. Total volatility is the annualized standard deviation of daily returns within a month. A stock's market beta in a month is estimated by regressing its daily excess returns on market excess returns. To account for nonsynchronous prices we include both current and 4 lagged market excess returns in the regressions, estimating beta as the sum of the slopes on all lags, imposing the constraint that lags $2-4$ have the same slope (Lewellen and Nagel, 2006). Idiosyncratic volatility is the annualized standard deviation of the residuals from these regressions. Price is the stock's nominal price on the last day of the month. Market capitalization is the product of price and shares outstanding. Institutional ownership is the sum of the number of shares of each stock held by $13 \mathrm{f}$ filers, divide by its shares outstanding, as of the end of the most recently completed quarter. Sales volatility is the standard deviation of year-over-year quarterly sales growth during the previous four quarters. Volume turnover is the number of shares traded in each month divided by the total number of shares outstanding. The market-to-book ratio is market capitalization (csho*prcc_f) plus the book value of assets (at) less shareholder equity (seq), all divided by the book value of assets (at). Book leverage is short-term and long-term debt (dlc + dltt) divided by the book value of assets (at). The bid-ask spread percentage is $100 \times \frac{A s k-B i d}{\text { Ask }}$. The intraday price range percentage is $100 \times \frac{\text { High-Low }}{\text { High }}$.

\begin{tabular}{lcccc}
\hline & Obs & Mean & Median & Std Dev \\
\hline Total Volatility (Annualized) & $3,254,302$ & 0.510 & 0.390 & 0.450 \\
Idiosyncratic Volatility (Annualized) & $3,254,302$ & 0.448 & 0.334 & 0.415 \\
Market Beta & $3,254,302$ & 0.941 & 0.809 & 3.069 \\
Price & $3,254,302$ & 18.85 & 13.50 & 19.13 \\
Market Capitalization (Millions) & $3,254,302$ & 1179.9 & 64.47 & 8800.6 \\
Insitutional Ownership & $2,165,251$ & 0.346 & 0.272 & 0.292 \\
Sales Volatility & $2,316,178$ & 0.273 & 0.0966 & 0.691 \\
Volume Turnover & $2,996,292$ & 0.0882 & 0.0382 & 0.204 \\
Market-to-Book Ratio & $2,240,583$ & 1.977 & 1.252 & 18.19 \\
Book Leverage & $2,130,604$ & 0.232 & 0.191 & 0.278 \\
Bid Ask Spread (Percentage) & $2,246,545$ & 4.840 & 2.525 & 17.63 \\
Intraday Price Range (Percentage) & $2,555,175$ & 3.586 & 2.826 & 2.726 \\
\hline
\end{tabular}




\section{Table 2}

Baseline Results: Total Volatility

This table explores how return volatility varies with share price. Using data at the stock-month level, regressions of the following form are estimated:

$$
\log \left(\operatorname{vol}_{i, t}\right)=\beta_{0}+\beta_{1} \log \left(\text { price }_{i, t-1}\right)+\text { controls }+\tau_{t}+\epsilon_{i t},
$$

where $\operatorname{vol}_{i, t}$ represents the volatility of stock $i$ in month $t$, price $_{i, t-1}$ represents the stock's price at the end of month $t-1$, and $\tau_{t}$ represents year-month fixed effects. Total volatility is the annualized standard deviation of daily returns within a month. Control variables can include the log of the firm's size (measured as total market equity) at end of the previous month or indicator variables for 20 size categories based on the market capitalization of the stock relative to the size breakpoints for each year-month from the Ken French Data Library. The sample excludes observations with extreme lagged prices (the bottom and top $1 \%$ of prices each month). Standard errors are double-clustered by stock and year-month. ***, and *** denote statistical significance at the $10 \%, 5 \%$, and $1 \%$ level, respectively.

Panel A: Cross-Section

\begin{tabular}{|c|c|c|c|c|}
\hline & \multicolumn{4}{|c|}{ Log(Total Volatility) } \\
\hline & (1) & $(2)$ & $(3)$ & (4) \\
\hline Log(Lagged Price) & $\begin{array}{l}-0.326^{* * *} \\
(0.00339)\end{array}$ & & $\begin{array}{l}-0.332^{* * *} \\
(0.00446)\end{array}$ & $\begin{array}{l}-0.339^{* * *} \\
(0.00405)\end{array}$ \\
\hline Log(Lagged Size) & & $\begin{array}{l}-0.146^{* * *} \\
(0.00235)\end{array}$ & $\begin{array}{c}0.00431 \\
(0.00311)\end{array}$ & \\
\hline Year-Month FE & Yes & Yes & Yes & Yes \\
\hline Size Category FE & No & No & No & Yes \\
\hline R-squared & 0.442 & 0.328 & 0.442 & 0.445 \\
\hline Observations & $3,254,302$ & $3,254,302$ & $3,254,302$ & $3,254,302$ \\
\hline \multicolumn{5}{|c|}{ Panel B: Time Series } \\
\hline & \multicolumn{4}{|c|}{$\log ($ Total Volatility $)$} \\
\hline & $(1)$ & $(2)$ & $(3)$ & $(4)$ \\
\hline Log(Lagged Price) & $\begin{array}{l}-0.260^{* * *} \\
(0.00395)\end{array}$ & & $\begin{array}{l}-0.261^{* * *} \\
(0.00477)\end{array}$ & $\begin{array}{l}-0.274^{* * *} \\
(0.00403)\end{array}$ \\
\hline Log(Lagged Size) & & $\begin{array}{l}-0.160^{* * *} \\
(0.00334)\end{array}$ & $\begin{array}{c}0.000476 \\
(0.00383)\end{array}$ & \\
\hline Stock FE & Yes & Yes & Yes & Yes \\
\hline Year-Month FE & Yes & Yes & Yes & Yes \\
\hline Size Category FE & No & No & No & Yes \\
\hline R-squared & 0.588 & 0.565 & 0.588 & 0.588 \\
\hline Observations & $3,254,302$ & $3,254,302$ & $3,254,302$ & $3,254,302$ \\
\hline
\end{tabular}


Table 3

Baseline Results: Idiosyncratic Volatility and Market Beta

This table repeats the analysis of Table 2, Panel A, using idiosyncratic volatility and absolute market beta as the outcome variable. Variables are as defined in Table 1 and 2. Standard errors are double-clustered by stock and year-month. ${ }^{*}, * *$, and ${ }^{* * *}$ denote statistical significance at the $10 \%, 5 \%$, and $1 \%$ level, respectively.

Panel A: Idiosyncratic Volatility

\begin{tabular}{|c|c|c|c|c|}
\hline & \multicolumn{4}{|c|}{ Log(Idiosyncratic Volatility) } \\
\hline & (1) & $(2)$ & $(3)$ & $(4)$ \\
\hline Log(Lagged Price) & $\begin{array}{l}-0.360^{* * *} \\
(0.00320)\end{array}$ & & $\begin{array}{l}-0.332^{* * *} \\
(0.00434)\end{array}$ & $\begin{array}{l}-0.346^{* * *} \\
(0.00399)\end{array}$ \\
\hline Log(Lagged Size) & & $\begin{array}{l}-0.173^{* * *} \\
(0.00217)\end{array}$ & $\begin{array}{c}-0.0224^{* * *} \\
(0.00308)\end{array}$ & \\
\hline Year-Month FE & Yes & Yes & Yes & Yes \\
\hline Size Category FE & No & No & No & Yes \\
\hline R-squared & 0.469 & 0.363 & 0.470 & 0.473 \\
\hline Observations & $3,254,302$ & $3,254,302$ & $3,254,302$ & $3,254,302$ \\
\hline \multicolumn{5}{|c|}{ Panel B: Market Beta } \\
\hline & \multicolumn{4}{|c|}{$\log (\mid$ Beta $\mid)$} \\
\hline & $(1)$ & $(2)$ & $(3)$ & $(4)$ \\
\hline Log(Lagged Price) & $\begin{array}{l}-0.228^{* * *} \\
(0.00395)\end{array}$ & & $\begin{array}{l}-0.325^{* * *} \\
(0.00521)\end{array}$ & $\begin{array}{l}-0.319^{* * *} \\
(0.00465)\end{array}$ \\
\hline Log(Lagged Size) & & $\begin{array}{c}-0.0717^{* * *} \\
(0.00276)\end{array}$ & $\begin{array}{l}0.0757^{* * *} \\
(0.00375)\end{array}$ & \\
\hline Year-Month FE & Yes & Yes & Yes & Yes \\
\hline Size Category FE & No & No & No & Yes \\
\hline R-squared & 0.097 & 0.068 & 0.102 & 0.103 \\
\hline Observations & $3,254,302$ & $3,254,302$ & $3,254,302$ & $3,254,302$ \\
\hline
\end{tabular}




\section{Table 4}

The Leverage Effect Puzzle: Past Returns versus Price

Panel A of this table repeats the analysis of Table 2, Panel A, controlling for a stock's return in the 12 months leading up to month $t$. The sample is limited to observations where the dependent variable and independent variables in all columns are non-missing. In column 4 we control separately for past returns in each the previous 12 months. Panel B restricts the sample to firms with zero book leverage (according to COMPUSTAT data) in the quarter before month $t$. Variables are as defined in Table 1 and 2. Standard errors are double-clustered by stock and year-month. ${ }^{*}, * *$, and ${ }^{* * *}$ denote statistical significance at the $10 \%$, $5 \%$, and $1 \%$ level, respectively.

Panel A: Full Sample

\begin{tabular}{|c|c|c|c|c|}
\hline & \multicolumn{4}{|c|}{ Log(Total Volatility) } \\
\hline & $(1)$ & $(2)$ & $(3)$ & $(4)$ \\
\hline Log(Lagged Price) & $\begin{array}{l}-0.339^{* * *} \\
(0.00412)\end{array}$ & & $\begin{array}{l}-0.332^{* * *} \\
(0.00465)\end{array}$ & $\begin{array}{l}-0.331^{* * *} \\
(0.00466)\end{array}$ \\
\hline Log(1+Past 12-Month Return $)$ & & $\begin{array}{c}-0.240^{* * *} \\
(0.0101)\end{array}$ & $\begin{array}{c}-0.0309^{* * *} \\
(0.00902)\end{array}$ & \\
\hline Year-Month FE & Yes & Yes & Yes & Yes \\
\hline Size Category FE & Yes & Yes & Yes & Yes \\
\hline Past 12 Monthly Returns & No & No & No & Yes \\
\hline R-squared & 0.458 & 0.346 & 0.458 & 0.459 \\
\hline Observations & $2,966,196$ & $2,966,196$ & $2,966,196$ & $2,966,196$ \\
\hline \multicolumn{5}{|c|}{ Panel B: Zero Leverage Subsample } \\
\hline & \multicolumn{4}{|c|}{$\log ($ Total Volatility $)$} \\
\hline & $(1)$ & $(2)$ & $(3)$ & $(4)$ \\
\hline Log(Lagged Price) & $\begin{array}{l}-0.288^{* * *} \\
(0.00800)\end{array}$ & & $\begin{array}{l}-0.286^{* * *} \\
(0.00851)\end{array}$ & $\begin{array}{l}-0.285^{* * *} \\
(0.00855)\end{array}$ \\
\hline Log $(1+$ Past 12-Month Return $)$ & & $\begin{array}{c}-0.160^{* * *} \\
(0.0139)\end{array}$ & $\begin{array}{c}-0.00970 \\
(0.0122)\end{array}$ & \\
\hline Year-Month FE & Yes & Yes & Yes & Yes \\
\hline Size Category FE & Yes & Yes & Yes & Yes \\
\hline Past 12 Monthly Returns & No & No & No & Yes \\
\hline R-squared & 0.357 & 0.246 & 0.357 & 0.358 \\
\hline Observations & 201,509 & 201,509 & 201,509 & 201,509 \\
\hline
\end{tabular}




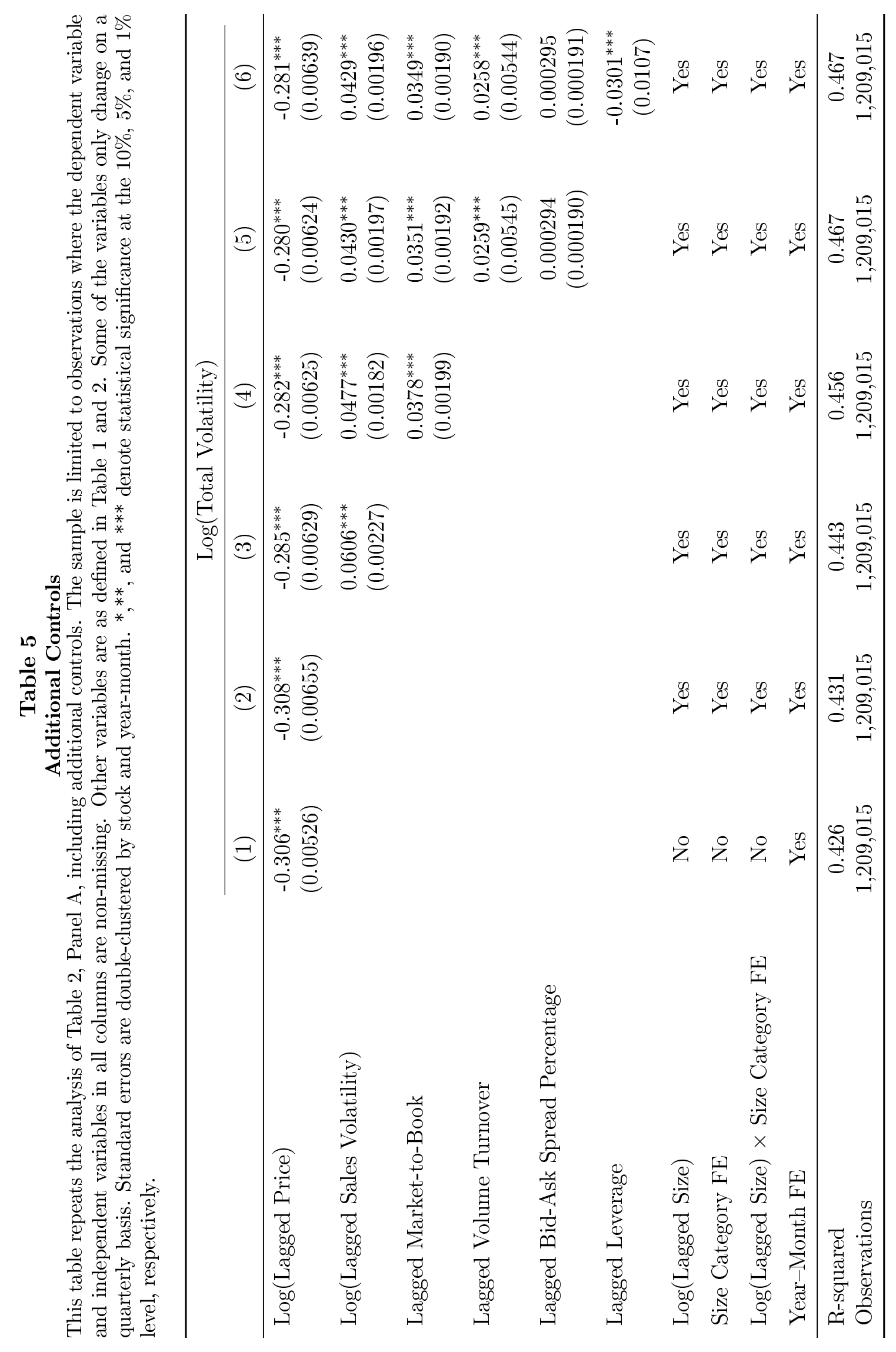




\section{Table 6}

Alternative Volatility Measures

This table repeats the analysis of Table 2, Panel A, but uses alternative linear measures of return volatility that are robust to tick size distortions (Hau, 2006). In column (1), volatility is measured as the mean intraday price range percentage $\left(100 \times \frac{H i g h-L o w}{H i g h}\right)$ over all trading days in a stock-month. In column (2), volatility is measured as the mean absolute deviation $(\mid$ Ret $-\overline{\text { Ret }} \mid)$ over all trading days in stock-month. In column (3), volatility is measured as the mean absolute return ( $\mid$ Ret $\mid)$ over all trading days in a stock-month. Standard errors are double-clustered by stock and year-month. ${ }^{*}{ }^{* *}$, and $* * *$ denote statistical significance at the $10 \%, 5 \%$, and $1 \%$ level, respectively.

$\log ($ Volatility Measure)

(1)

$(2)$

(3)

Intraday Range Absolute Deviation

Absolute Return

\begin{tabular}{lccc}
\hline Log(Lagged Price) & $-0.410^{* * *}$ & $-0.325^{* * *}$ & $-0.312^{* * *}$ \\
& $(0.00513)$ & $(0.00472)$ & $(0.00542)$ \\
Year-Month FE & Yes & Yes & Yes \\
Size Category FE & Yes & Yes & Yes \\
\hline R-squared & 0.507 & 0.397 & 0.353 \\
Observations & $2,555,207$ & $3,254,302$ & $3,254,302$ \\
\hline
\end{tabular}

Table 7

Institutional Ownership

This table repeats the analysis of Table 2 Panel A, with the addition of institutional ownership as a control variable, as well as institutional ownership interacted with price. Institutional ownership is computed as defined in Table 1, and is updated quarterly. Standard errors are double-clustered by stock and year-month. ${ }^{*}, * *$, and ${ }^{* * *}$ denote statistical significance at the $10 \%, 5 \%$, and $1 \%$ level, respectively.

\begin{tabular}{lccc}
\hline & $(1)$ & $(2)$ & $(3)$ \\
& $\log ($ Total Volatility) & $\log ($ Idios. Vol. $)$ & $\log (\mid$ Beta $\mid)$ \\
\hline Log(Lagged Price) & $-0.384^{* * *}$ & $-0.381^{* * *}$ & $-0.393^{* * *}$ \\
& $(0.00509)$ & $(0.00511)$ & $(0.00582)$ \\
Log(Lagged Price) $)$ Lagged Inst. Own. & $0.169^{* * *}$ & $0.137^{* * *}$ & $0.174^{* * *}$ \\
& $(0.0108)$ & $(0.0107)$ & $(0.0128)$ \\
Lagged Inst. Own. & $-0.311^{* * *}$ & $-0.279^{* * *}$ & $-0.126^{* * *}$ \\
& $(0.0323)$ & $(0.0315)$ & $(0.0405)$ \\
Year-Month FE & Yes & Yes & Yes \\
Size Category FE & Yes & Yes & Yes \\
\hline R-squared & 0.432 & 0.462 & 0.112 \\
Observations & $2,113,118$ & $2,113,118$ & $2,113,118$ \\
\hline
\end{tabular}


Table 8

Stock Characteristics Around Splits

This table shows mean institutional ownership and sales volatility before and after 2-for-1 stock splits, as well as the difference. Variables are as defined in Table 1 and 2. Before (after) split institutional ownership refers to institutional ownership based on the last (first) observed 13f filing for each stock prior to (following) the split. Before (after) split sales volatility refers to sales volatility based on the most last (first) four completed quarters prior to (following) the split.

\begin{tabular}{|c|c|c|c|c|c|c|c|c|c|}
\hline & \multicolumn{3}{|c|}{ Before Split } & \multicolumn{3}{|c|}{ After Split } & \multicolumn{3}{|c|}{ Difference } \\
\hline & Obs & Mean & Std Dev & Obs & Mean & Std Dev & Obs & Mean & Std Dev \\
\hline Inst. Ownership & 4,075 & 0.481 & 0.286 & 4,138 & 0.471 & 0.276 & 8,213 & 0.010 & 0.006 \\
\hline Sales Volatility & 4,042 & 0.203 & 1.646 & 4,215 & 0.192 & 1.585 & 8,257 & 0.011 & 0.036 \\
\hline
\end{tabular}

Table 9

Response to News Events Identified Through Textual Analysis

This table shows the relation between the return response to a news event and the nominal price of a stock prior to the event. Cumulative abnormal returns (CAR) are computed from trading day -1 to day +1 relative to the event. Benchmark returns during the event window are based on the market model. Market betas are estimated based on returns in days -150 to -100 relative to the event date. Lagged Price is the price of the stock on trading day -2 . News events come from Boudoukh et al. (2018). The first two columns limit the sample to categorized firm-specific news events, which are events which Boudoukh et al. (2018) are able to categorize using an algorithm. The final two columns limit the sample to non-categorized news events, which are events that Boudoukh et al. (2018) are not able to categorize. Other variables are as defined in Table 1 and 2. Standard errors are double-clustered by stock and year-month. ${ }^{*}, * *$, and ${ }^{* * *}$ denote statistical significance at the $10 \%, 5 \%$, and $1 \%$ level, respectively.

\begin{tabular}{lccccc}
\hline & \multicolumn{4}{c}{$\log (|\mathrm{CAR}|)$} \\
\cline { 2 - 5 } & \multicolumn{2}{c}{ Categorized News } & & \multicolumn{2}{c}{ Other News } \\
\cline { 2 - 3 } \cline { 5 - 5 } & $(1)$ & & $(2)$ & & $(3)$ \\
\hline Log(Lagged Price) & $-0.299^{* * *}$ & $-0.217^{* * *}$ & & $-0.279^{* * *}$ & $-0.208^{* * *}$ \\
Year-Month FE & $(0.0161)$ & $(0.0161)$ & & $(0.0156)$ & $(0.0169)$ \\
Size Category FE & Yes & Yes & & Yes & Yes \\
\hline R-squared & No & Yes & & No & Yes \\
Observations & 0.105 & 0.115 & & 0.106 & 0.111 \\
\hline
\end{tabular}




\section{Table 10}

\section{Response to Earnings Announcements}

Panel A of this table shows the relation between the return response to an earnings announcement and the nominal price of a stock prior to the announcement. Cumulative abnormal returns (CAR) are computed from trading day -1 to day +1 relative to the announcement. Benchmark returns during the event window are based on the market model. Market betas are estimated based on returns in days -150 to -100 relative to the announcement date. The variable Lagged Price is the price of the stock on trading day -2 . Analyst count fixed effects are fixed effects for the number of analysts that made an earnings forecast prior to the announcement. The first two columns of Panel B shows results from regressions of the return response to an announcement on its standardized unexpected earnings (SUE) decile rank, its lagged price quintile, and all interactions. The last two columns of Panel B limit the sample to announcements in the top and bottom SUE decile and show results from regressions of the return response to an announcement on the top SUE decile indicator, lagged price quintile, and all interactions. Standardized unexpected earnings are defined as the difference between announced earnings and mean analyst expectations, divided by the standard deviation of analyst expectations. To avoid using stale information in our measure of analyst expectations, we exclude analyst's forecasts that are made more than 60 days prior to the announcement. Therefore, SUE is only defined for announcements with multiple recent analysts forecasts. Other variables are as defined in Table 1 and 2. Standard errors are double-clustered by stock and year-month. ${ }^{*}, * *$, and ${ }^{* * *}$ denote statistical significance at the $10 \%, 5 \%$, and $1 \%$ level, respectively.

\section{Panel A: Return Response on Earnings Announcement Days}

\begin{tabular}{lcccc}
\hline & \multicolumn{4}{c}{$\log (|\mathrm{CAR}|)$} \\
\cline { 2 - 5 } & $(1)$ & $(2)$ & $(3)$ & $(4)$ \\
\hline Log(Lagged Price) & $-0.223^{* * *}$ & $-0.232^{* * *}$ & $-0.271^{* * *}$ & $-0.210^{* * *}$ \\
& $(0.00747)$ & $(0.0102)$ & $(0.00791)$ & $(0.00944)$ \\
Year-Month FE & Yes & Yes & Yes & Yes \\
Size Category FE & No & Yes & No & Yes \\
Analyst Count FE & No & No & Yes & Yes \\
\hline R-squared & 0.067 & 0.071 & 0.072 & 0.082 \\
Observations & 339,736 & 339,736 & 339,736 & 339,736 \\
\hline
\end{tabular}


Table 10

(Continued)

Panel B: Return Response to Earnings Surprises

\begin{tabular}{|c|c|c|c|c|}
\hline & \multicolumn{4}{|c|}{$\log (1+\mathrm{CAR})$} \\
\hline & \multicolumn{2}{|c|}{ All SUE Deciles } & \multicolumn{2}{|c|}{ Extreme SUE Deciles } \\
\hline & (1) & $(2)$ & $(3)$ & $(4)$ \\
\hline SUE Decile Rank & $\begin{array}{l}0.00994^{* * *} \\
(0.000532)\end{array}$ & $\begin{array}{l}0.00995^{* * *} \\
(0.000533)\end{array}$ & & \\
\hline SUE Decile Rank $\times$ Lagged Price Quintile 2 & $\begin{array}{l}-0.000366 \\
(0.000512)\end{array}$ & $\begin{array}{l}-0.000385 \\
(0.000514)\end{array}$ & & \\
\hline SUE Decile Rank $\times$ Lagged Price Quintile 3 & $\begin{array}{r}-0.00180^{* * *} \\
(0.000550)\end{array}$ & $\begin{array}{r}-0.00180^{* * *} \\
(0.000551)\end{array}$ & & \\
\hline SUE Decile Rank $\times$ Lagged Price Quintile 4 & $\begin{array}{r}-0.00360^{* * *} \\
(0.000538)\end{array}$ & $\begin{array}{c}-0.00359^{* * *} \\
(0.000539)\end{array}$ & & \\
\hline SUE Decile Rank $\times$ Lagged Price Quintile 5 & $\begin{aligned}-0.00443^{* * *} \\
(0.000548)\end{aligned}$ & $\begin{array}{r}-0.00442^{* * *} \\
(0.000549)\end{array}$ & & \\
\hline SUE Top Decile & & & $\begin{array}{l}0.0973^{* * *} \\
(0.00668)\end{array}$ & $\begin{array}{l}0.0973^{* * *} \\
(0.00672)\end{array}$ \\
\hline SUE Top Decile $\times$ Lagged Price Quintile 2 & & & $\begin{array}{l}-0.00250 \\
(0.00700)\end{array}$ & $\begin{array}{l}-0.00313 \\
(0.00705)\end{array}$ \\
\hline SUE Top Decile $\times$ Lagged Price Quintile 3 & & & $\begin{array}{l}-0.0141^{*} \\
(0.00759)\end{array}$ & $\begin{array}{l}-0.0143^{*} \\
(0.00760)\end{array}$ \\
\hline SUE Top Decile $\times$ Lagged Price Quintile 4 & & & $\begin{array}{r}-0.0324^{* * *} \\
(0.00727)\end{array}$ & $\begin{array}{r}-0.0319^{* * *} \\
(0.00730)\end{array}$ \\
\hline SUE Top Decile $\times$ Lagged Price Quintile 5 & & & $\begin{array}{r}-0.0436^{* * *} \\
(0.00711)\end{array}$ & $\begin{array}{r}-0.0430^{* * *} \\
(0.00714)\end{array}$ \\
\hline Lagged Price Quintile FE & Yes & Yes & Yes & Yes \\
\hline Year-Month FE & Yes & Yes & Yes & Yes \\
\hline Size Category FE & No & Yes & No & Yes \\
\hline Analyst Count FE & No & Yes & No & Yes \\
\hline R-squared & 0.081 & 0.082 & 0.162 & 0.165 \\
\hline Observations & 89,279 & 89,279 & 17,650 & 17,650 \\
\hline
\end{tabular}




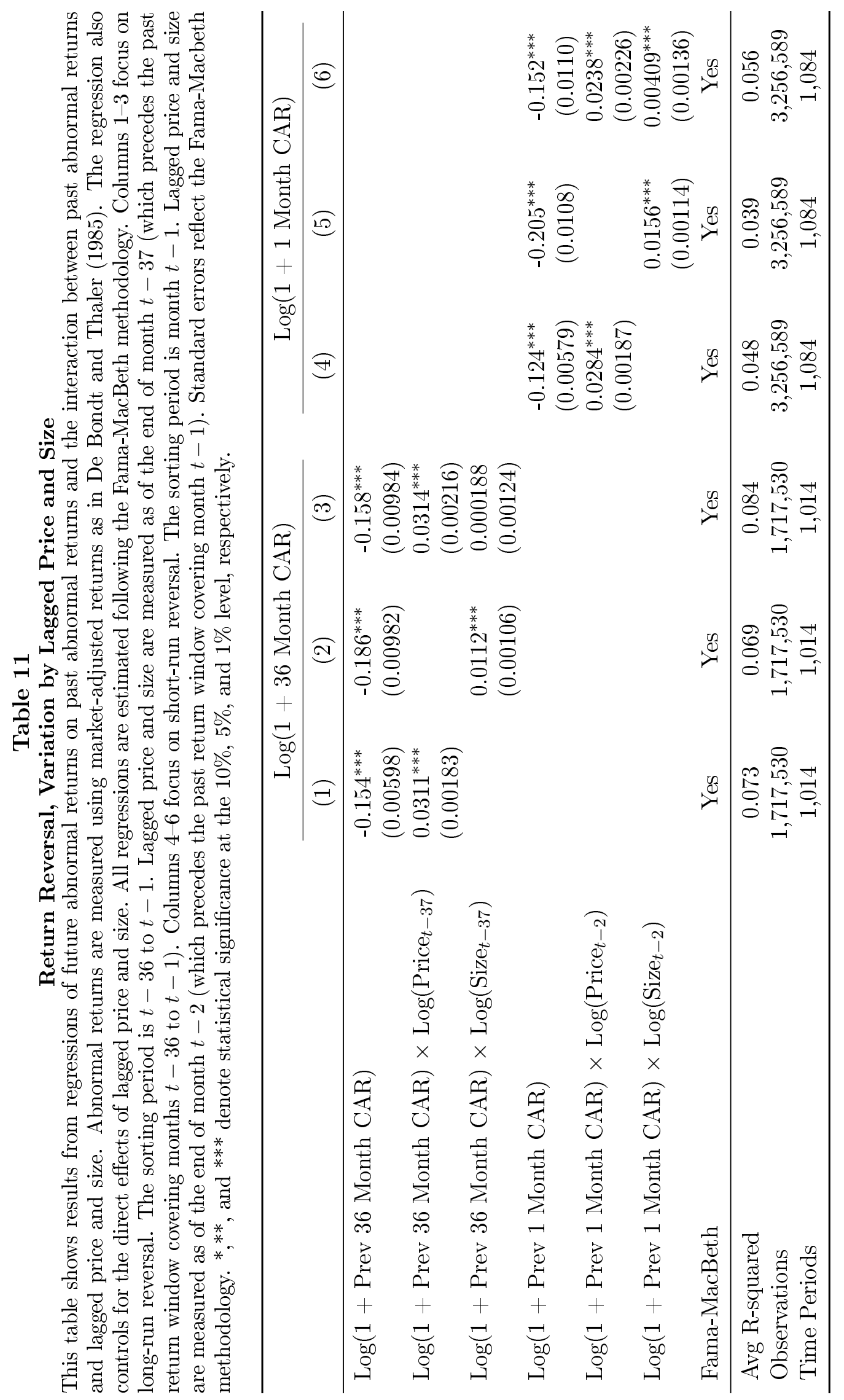




\section{A Supplemental Figures and Tables}

\section{Figure A1}

Splits: Large-Cap Subsample

This figure shows that the patterns relating to splits discussed in Section 4.2 are not driven by small-cap stocks. We re-estimate Figures 5 and 6 using data restricted to firms in Fama French size categories 11 to 20 as of the month prior to the split. The sample is restricted to 2 -for-1 stock splits.

\section{Panel A: Intraday Price Range}

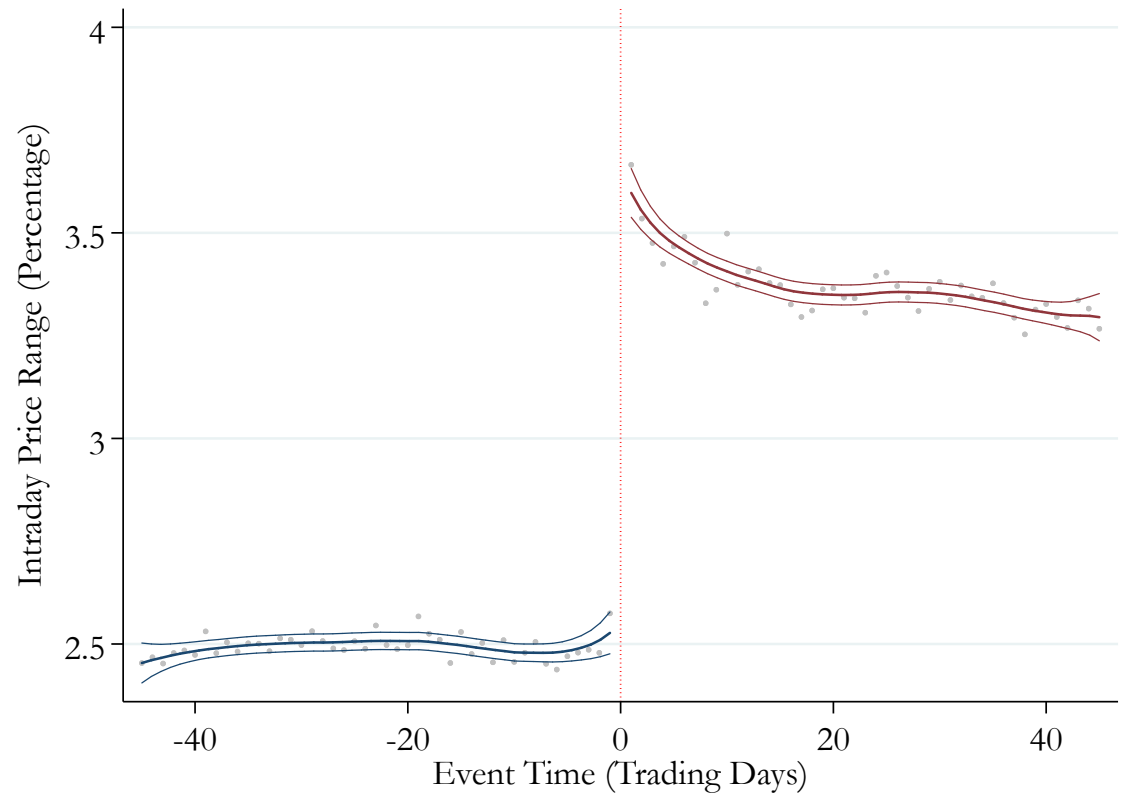

Panel B: Total Volatility

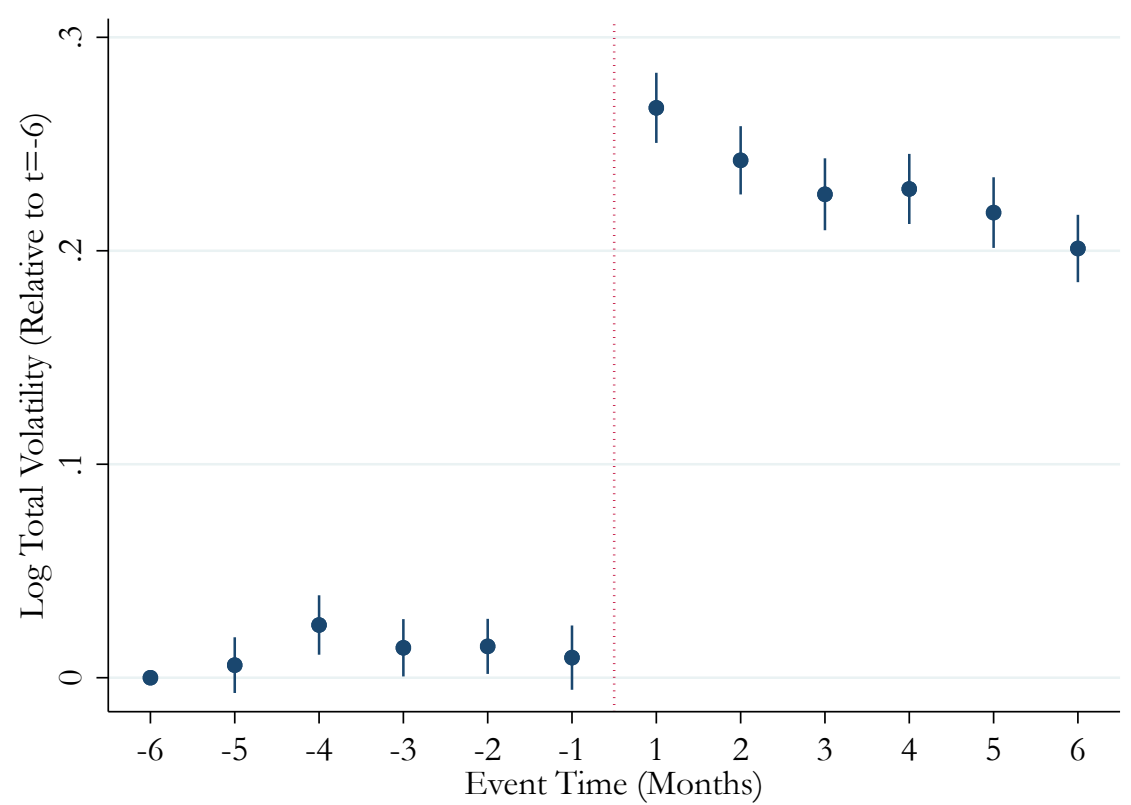


Figure A2

Splits: Large-Cap Subsample (Continued)

Panel A: Market Beta

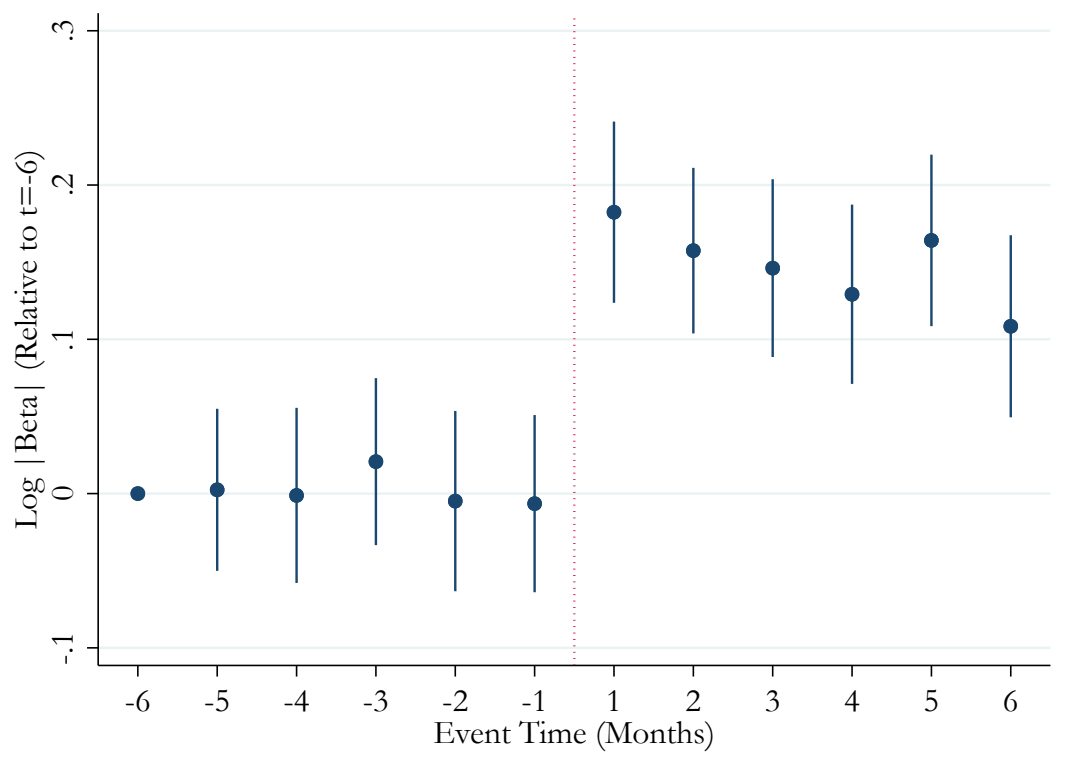

Panel B: Volume Turnover

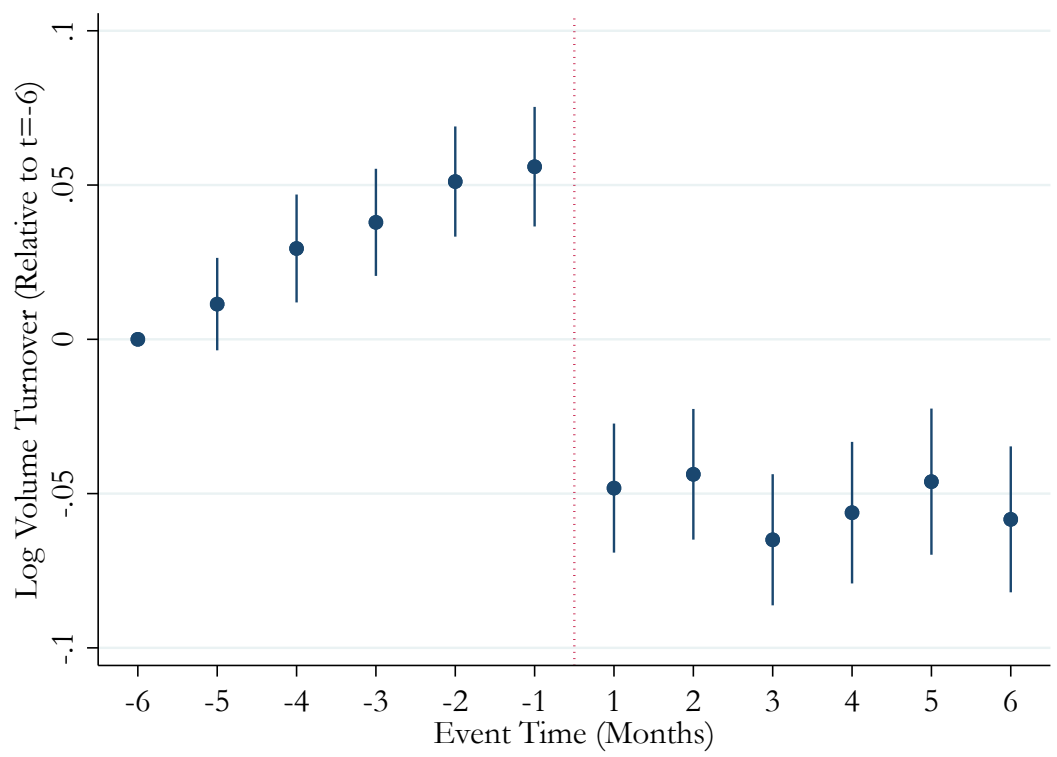


Table A1

Baseline Results: Market Beta-Positive Only

This table repeats the analysis of Table 3 , Panel B, limiting the sample to observations with positive estimated market betas. Standard errors are double-clustered by stock and year-month. ${ }^{*}, * *$, and ${ }^{* * *}$ denote statistical significance at the $10 \%, 5 \%$, and $1 \%$ level, respectively.

\begin{tabular}{lcccc}
\hline & \multicolumn{4}{c}{ Log(Beta) } \\
\cline { 2 - 5 } & $(1)$ & $(2)$ & $-0.297^{* * *}$ & $-0.296^{* * *}$ \\
\hline Log(Lagged Price) & $-0.202^{* * *}$ & & $(0.00550)$ & $(0.00493)$ \\
& $(0.00369)$ & $-0.0592^{* * *}$ & $0.0720^{* * *}$ & \\
Log(Lagged Size) & & $(0.00244)$ & $(0.00375)$ & Yes \\
Year-Month FE & Yes & Yes & Yes & Yes \\
Size Category FE & No & No & No & 0.097 \\
R-squared & 0.090 & 0.064 & 0.095 & $2,315,198$ \\
Observations & $2,315,198$ & $2,315,198$ & $2,315,198$ & \\
\hline
\end{tabular}




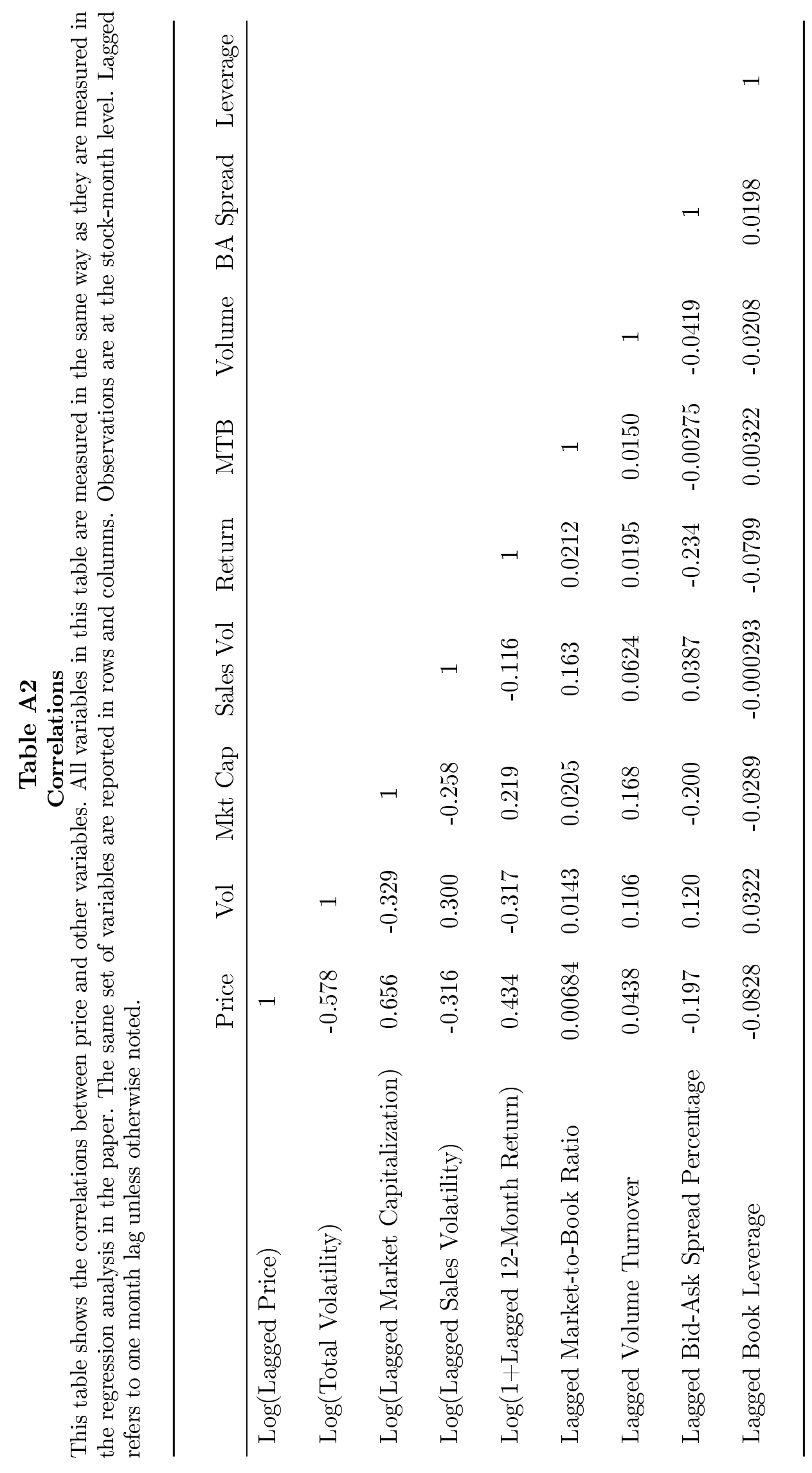




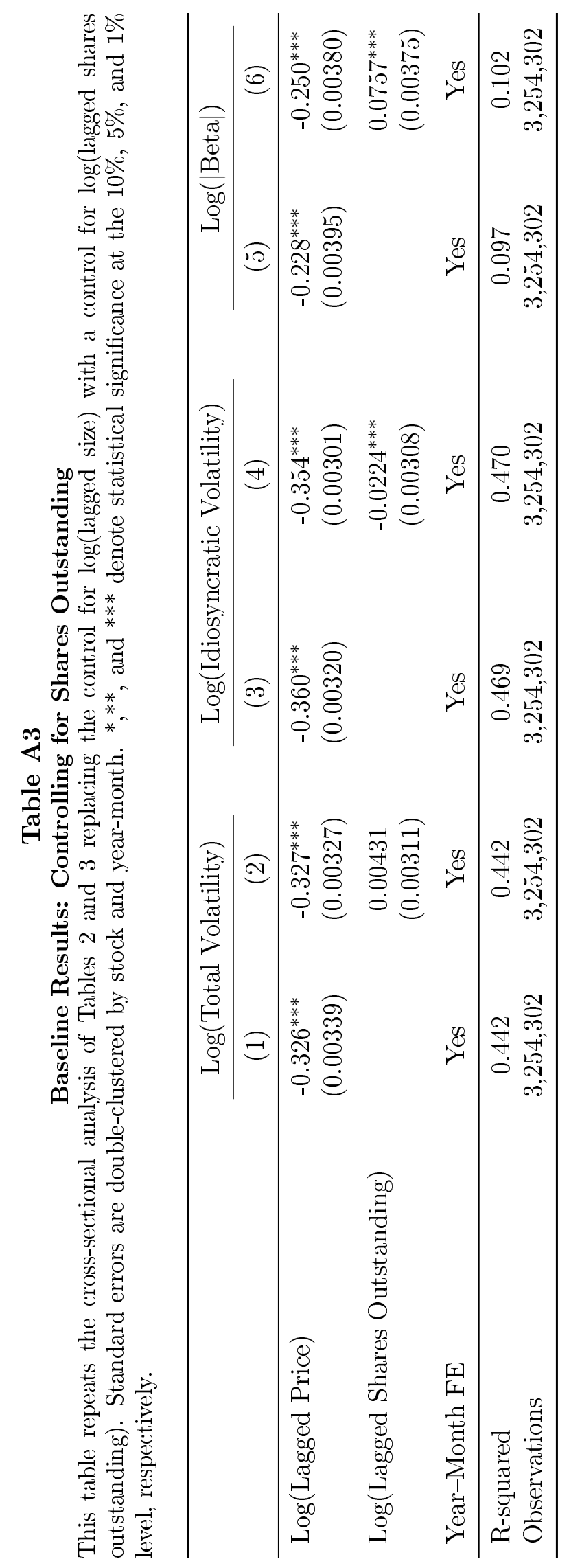




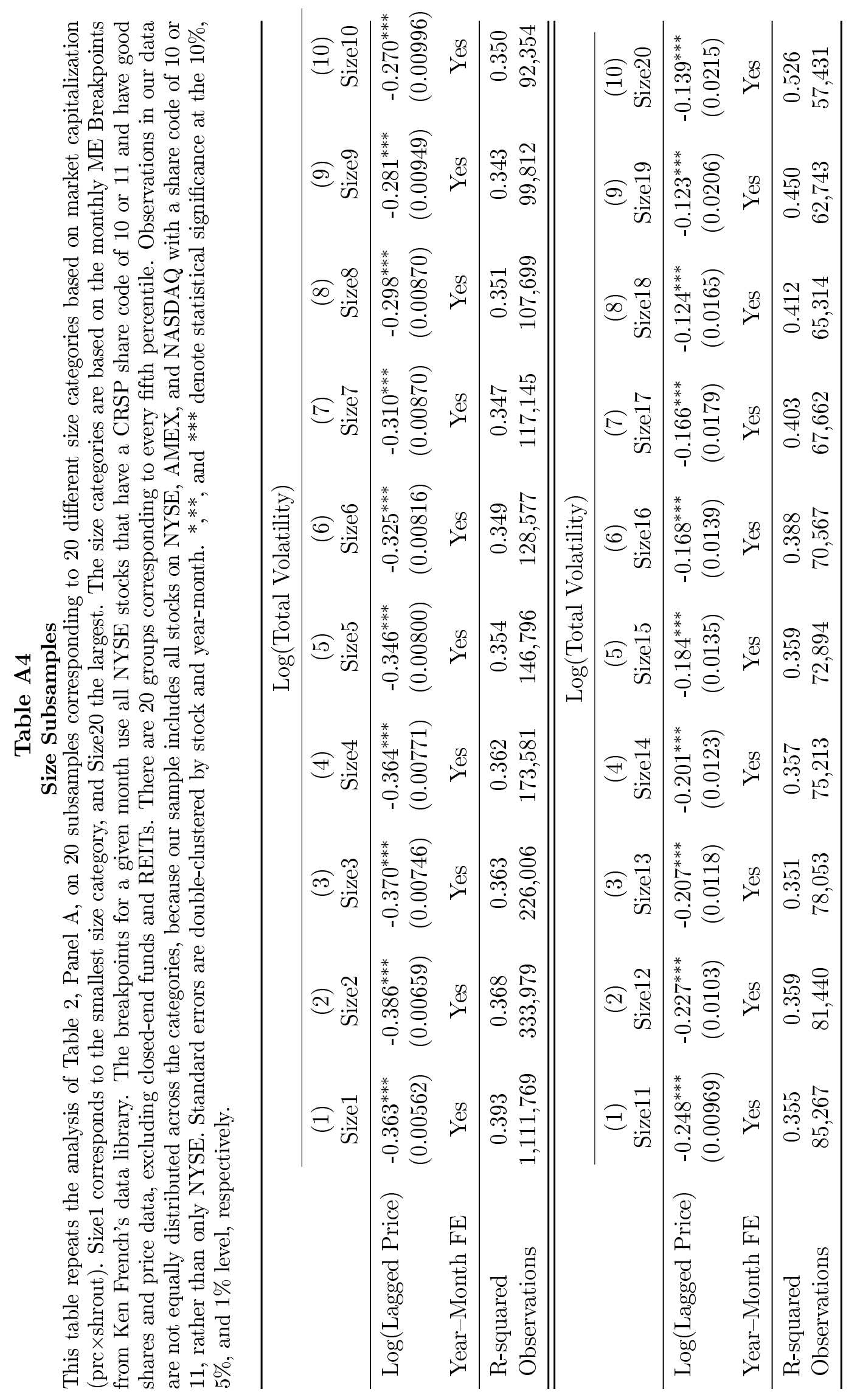




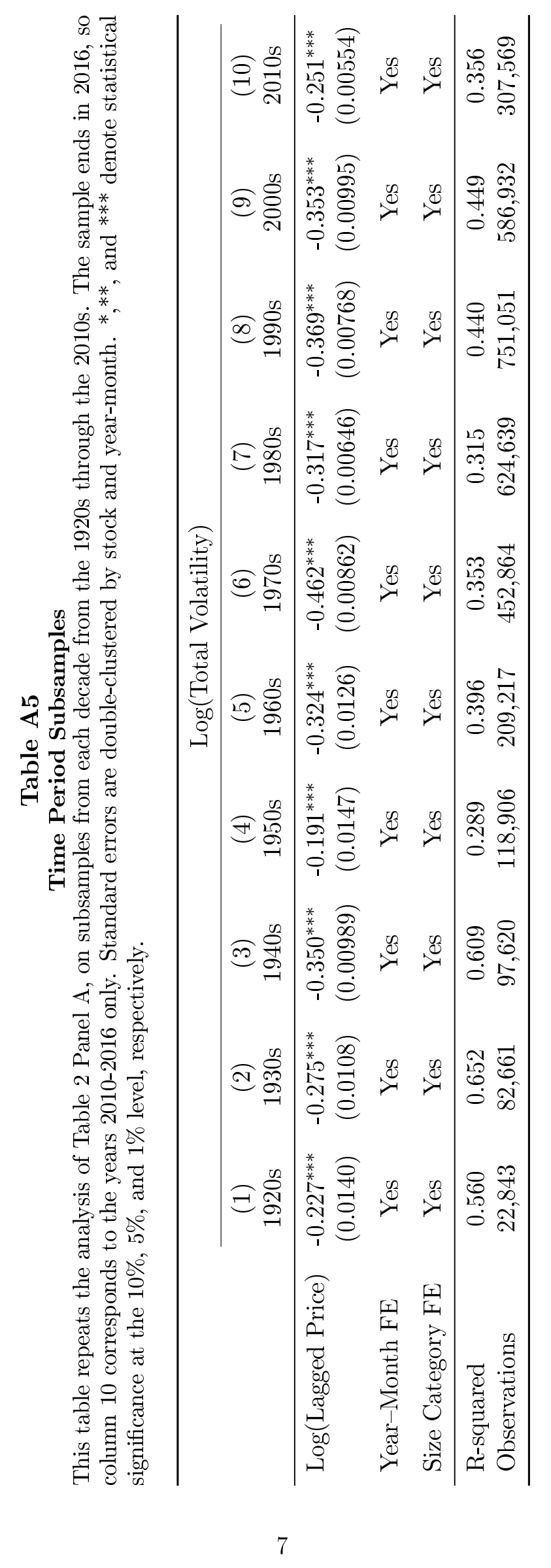




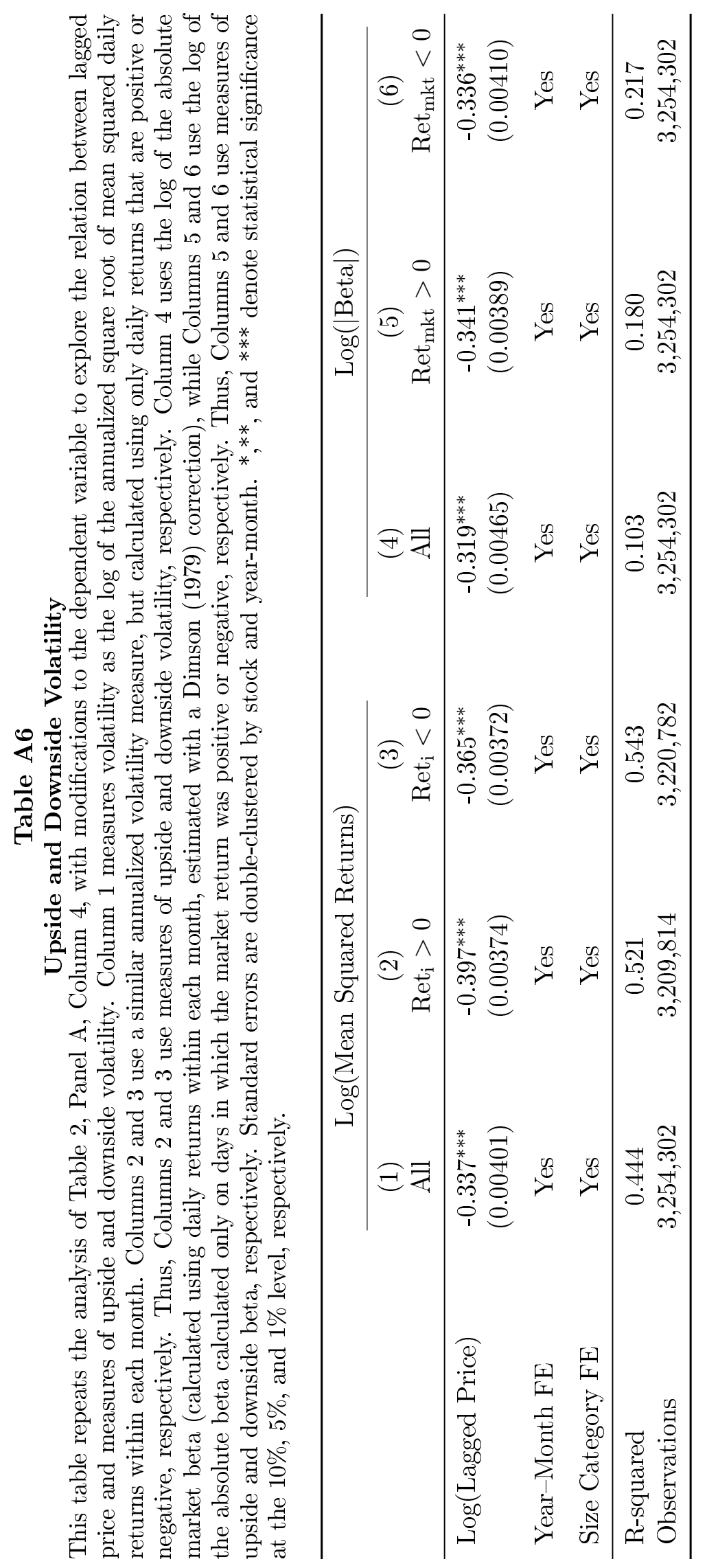


Table A7

Regression Discontinuity: Intraday Price Range Around Stock Splits

This table explores the pattern of volatility around 2-for- 1 stock splits. We examine 45 days before and after the split. Variables are as defined in Table 1. Control functions on each side of the cutoff are estimated nonparametrically using local linear regression. The first three columns use a triangular kernel. The last three columns use a rectangular kernel. Bandwidths are selected using one common MSE-optimal bandwidth selector in columns (1) and (4). Other bandwidths are shown in the remaining columns. The estimated coefficient represents the size of the discontinuity at the split date, as illustrated in Figure 5.

\begin{tabular}{lcccccc}
\hline & \multicolumn{5}{c}{ Intraday Price Range (Percentage) } \\
\cline { 2 - 7 } & $(1)$ & $(2)$ & $(3)$ & $(4)$ & $(5)$ & $(6)$ \\
\hline Discontinuity at Split Date & $1.361^{* * *}$ & $1.377^{* * *}$ & $1.374^{* * *}$ & $1.368^{* * *}$ & $1.350^{* * *}$ & $1.352^{* * *}$ \\
& $(0.0475)$ & $(0.0678)$ & $(0.0408)$ & $(0.0437)$ & $(0.0545)$ & $(0.0352)$ \\
\hline Degree Local Poly & 1 & 1 & 1 & 1 & 1 & 1 \\
Bandwidth & 7.933 & 5 & 10 & 7.933 & 5 & 10 \\
Kernel & Triangular & Triangular & Triangular & Uniform & Uniform & Uniform \\
Observations & 573,778 & 573,778 & 573,778 & 573,778 & 573,778 & 573,778 \\
\hline
\end{tabular}


Table A8

Volatility Around Stock Splits

The odd columns of this table show the results of Figure 6 in tabular format. The even columns also estimate the coefficient on a single Post ${ }_{i, t}$ indicator, equal to one in event months in the 6 months following a split and 0 in the 6 months preceding a split. Standard errors are double-clustered by stock and year-month. $*, * *$, and $* * *$ denote statistical significance at the $10 \%, 5 \%$, and $1 \%$ level, respectively.

\begin{tabular}{|c|c|c|c|c|c|c|}
\hline & \multicolumn{2}{|c|}{ Log(Total Volatility) } & \multicolumn{2}{|c|}{ Log(Idiosyncratic Volatility) } & \multicolumn{2}{|c|}{$\log (\mid$ Beta $\mid)$} \\
\hline & $(1)$ & $(2)$ & (3) & $(4)$ & $(5)$ & $(6)$ \\
\hline $\mathbb{1}($ Event Month $\geq 0)$ & & $\begin{array}{c}0.216^{* * *} \\
(0.00443)\end{array}$ & & $\begin{array}{c}0.217^{\text {*** }} \\
(0.00466)\end{array}$ & & $\begin{array}{c}0.166^{* * *} \\
(0.00925)\end{array}$ \\
\hline $\mathbb{1}($ Event Month $=-5)$ & $\begin{array}{l}0.0172^{* * *} \\
(0.00565)\end{array}$ & & $\begin{array}{l}0.0205^{* * *} \\
(0.00590)\end{array}$ & & $\begin{array}{c}0.0231 \\
(0.0204)\end{array}$ & \\
\hline $\mathbb{1}($ Event Month $=-4)$ & $\begin{array}{l}0.0244^{* * *} \\
(0.00631)\end{array}$ & & $\begin{array}{l}0.0262^{* * *} \\
(0.00654)\end{array}$ & & $\begin{array}{c}0.0106 \\
(0.0207)\end{array}$ & \\
\hline $\mathbb{1}($ Event Month $=-3)$ & $\begin{array}{l}0.0218^{* * *} \\
(0.00620)\end{array}$ & & $\begin{array}{l}0.0211^{* * *} \\
(0.00621)\end{array}$ & & $\begin{array}{c}0.0200 \\
(0.0203)\end{array}$ & \\
\hline $\mathbb{1}($ Event Month $=-2)$ & $\begin{array}{l}0.0406^{* * *} \\
(0.00666)\end{array}$ & & $\begin{array}{l}0.0445^{* * *} \\
(0.00683)\end{array}$ & & $\begin{array}{c}0.0323 \\
(0.0224)\end{array}$ & \\
\hline $\mathbb{1}($ Event Month $=-1)$ & $\begin{array}{l}0.0459^{* * *} \\
(0.00675)\end{array}$ & & $\begin{array}{l}0.0459^{* * *} \\
(0.00698)\end{array}$ & & $\begin{array}{c}0.0633^{* * *} \\
(0.0206)\end{array}$ & \\
\hline $\mathbb{1}($ Event Month $=0)$ & $\begin{array}{c}0.242^{* * *} \\
(0.00694)\end{array}$ & & $\begin{array}{c}0.245^{* * *} \\
(0.00706)\end{array}$ & & $\begin{array}{l}0.239^{* * *} \\
(0.0217)\end{array}$ & \\
\hline $\mathbb{1}($ Event Month $=1)$ & $\begin{array}{c}0.291^{* * *} \\
(0.00706)\end{array}$ & & $\begin{array}{c}0.290^{* * *} \\
(0.00721)\end{array}$ & & $\begin{array}{l}0.229^{* * *} \\
(0.0216)\end{array}$ & \\
\hline $\mathbb{1}($ Event Month $=2)$ & $\begin{array}{c}0.258^{* * *} \\
(0.00741)\end{array}$ & & $\begin{array}{c}0.261^{* * *} \\
(0.00754)\end{array}$ & & $\begin{array}{l}0.197^{* * *} \\
(0.0201)\end{array}$ & \\
\hline $\mathbb{1}($ Event Month $=3)$ & $\begin{array}{c}0.234^{* * *} \\
(0.00766)\end{array}$ & & $\begin{array}{c}0.233^{* * *} \\
(0.00779)\end{array}$ & & $\begin{array}{l}0.176^{* * *} \\
(0.0210)\end{array}$ & \\
\hline $\mathbb{1}($ Event Month $=4)$ & $\begin{array}{c}0.232^{* * *} \\
(0.00721)\end{array}$ & & $\begin{array}{c}0.234^{* * *} \\
(0.00739)\end{array}$ & & $\begin{array}{l}0.172^{* * *} \\
(0.0212)\end{array}$ & \\
\hline $\mathbb{1}($ Event Month $=5)$ & $\begin{array}{c}0.217^{* * *} \\
(0.00721)\end{array}$ & & $\begin{array}{c}0.220^{* * *} \\
(0.00744)\end{array}$ & & $\begin{array}{l}0.178^{* * *} \\
(0.0201)\end{array}$ & \\
\hline $\mathbb{1}($ Event Month $=6)$ & $\begin{array}{c}0.212^{* * *} \\
(0.00720)\end{array}$ & & $\begin{array}{c}0.216^{* * *} \\
(0.00738)\end{array}$ & & $\begin{array}{l}0.139^{* * *} \\
(0.0217)\end{array}$ & \\
\hline Year-Month FE & Yes & Yes & Yes & Yes & Yes & Yes \\
\hline Stock FE & Yes & Yes & Yes & Yes & Yes & Yes \\
\hline R-squared & 0.648 & 0.646 & 0.628 & 0.627 & 0.195 & 0.195 \\
\hline Observations & 76,976 & 76,976 & 76,976 & 76,976 & 76,976 & 76,976 \\
\hline
\end{tabular}


Table A9

Volatility and Liquidity Around Stock Splits

This table explores how measures of liquidity change after splits, and whether changes in liquidity can explain the changes in volatility. All regressions follow the format in Table A8. The sample is restricted to the subsample of stocks for which bid-ask spread and volume turnover data are available. Volume turnover and bid-ask spread percentage are as defined in Table 1. Standard errors are double-clustered by stock and year-month. ${ }^{*}, * *$, and $* * *$ denote statistical significance at the $10 \%, 5 \%$, and $1 \%$ level, respectively.

\begin{tabular}{|c|c|c|c|c|}
\hline & \multirow{2}{*}{$\frac{\log \text { (Volume Turn.) }}{(1)}$} & \multirow{2}{*}{$\frac{\log (\text { B-A Spread })}{(2)}$} & \multicolumn{2}{|c|}{$\log$ (Volatility) } \\
\hline & & & $(3)$ & $(4)$ \\
\hline Post Split & $\begin{array}{c}-0.00818^{* * *} \\
(0.000792)\end{array}$ & $\begin{array}{l}0.310^{* * *} \\
(0.0239)\end{array}$ & $\begin{array}{c}0.200^{* * *} \\
(0.00604)\end{array}$ & $\begin{array}{l}0.196^{* * *} \\
(0.00524)\end{array}$ \\
\hline Volume Turn. & & & & $\begin{array}{l}2.576^{* * *} \\
(0.0565)\end{array}$ \\
\hline B-A Spread & & & & $\begin{array}{l}0.0820^{* * *} \\
(0.00450)\end{array}$ \\
\hline Year-Month FE & Yes & Yes & Yes & Yes \\
\hline Stock FE & Yes & Yes & Yes & Yes \\
\hline R-squared & 0.813 & 0.846 & 0.684 & 0.734 \\
\hline Observations & 40,121 & 40,121 & 40,121 & 40,121 \\
\hline
\end{tabular}

